OPEN ACCESS

Edited by: Anna Maria Pirttilä,

University of Oulu, Finland

Reviewed by:

Marcela Claudia Pagano,

Federal University of Minas Gerais,

Brazil

Cristina Silva Pereira

New University of Lisbon, Portugal

João Alencar Pamphile,

State University of Maringá, Brazil

${ }^{*}$ Correspondence:

Han-Bo Zhang

zhhb@ynu.edu.cn

${ }^{\dagger}$ These authors have contributed equally to this work

Specialty section:

This article was submitted to Fungi and Their Interactions,

a section of the journal

Frontiers in Microbiology

Received: 05 March 2019 Accepted: 04 December 2019 Published: 18 December 2019

Citation:

Fang K, Miao Y-F, Chen L, Zhou J, Yang $Z-P$, Dong $X-F$ and Zhang $H-B$ (2019) Tissue-Specific

and Geographical Variation

in Endophytic Fungi of Ageratina adenophora and Fungal Associations

With the Environment.

Front. Microbiol. 10:2919. doi: 10.3389/fmicb.2019.02919

\section{Tissue-Specific and Geographical Variation in Endophytic Fungi of Ageratina adenophora and Fungal Associations With the Environment}

\author{
Kai Fang ${ }^{1,2,3 t}$, Yi-Fang Miao ${ }^{4 t}$, Lin Chen 1,2,3, Jie Zhou 1,2, Zhi-Ping Yang ${ }^{1,2}$, \\ Xing-Fan Dong ${ }^{1,2}$ and Han-Bo Zhang ${ }^{1,2,3 *}$
}

\footnotetext{
1 State Key Laboratory for Conservation and Utilization of Bio-Resources in Yunnan, Yunnan University, Kunming, China, ${ }^{2}$ School of Life Sciences, Yunnan University, Kunming, China, ${ }^{3}$ School of Ecology and Environmental Science, Yunnan University, Kunming, China, ${ }^{4}$ Lu Cheng Center for Disease Control and Prevention, Changzhi, China
}

To understand the distribution of the cultivable fungal community in plant tissues and the associations of these fungi with their surrounding environments during the geographical expansion of an invasive plant, Ageratina adenophora, we isolated the cultivable fungi from 72 plant tissues, 12 soils, and 12 air samples collected from six areas in Yunnan Province, China. A total of 4066 isolates were investigated, including 1641 endophytic fungi, 233 withered leaf fungi, 1255 fungi from air, and 937 fungi from soil. These fungi were divided into 458 and 201 operational taxonomic units (OTUs) with unique and 97\% ITS gene sequence identity, respectively. Phylogenetic analysis showed that the fungi belonged to four phyla, including Ascomycota (94.20\%), Basidiomycota (2.71\%), Mortierellomycota (3.03\%), and Mucoromycota (0.07\%). The dominant genera of cultivable endophytic fungi were Colletotrichum (34.61\%), Diaporthe (17.24\%), Allophoma (8.03\%), and Fusarium (4.44\%). Colletotrichum and Diaporthe were primarily isolated from mature leaves, Allophoma from stems, and Fusarium from roots, indicating that the enrichment of endophytic fungi is tissue-specific and fungi rarely grew systemically within $A$. adenophora. In the surrounding environment, Alternaria (21.46\%), Allophoma (19.31\%), Xylaria (18.45\%), and Didymella (18.03\%) were dominant in the withered leaves, Cladosporium (22.86\%), Trichoderma (14.27\%), and Epicoccum (9.83\%) were dominant in the canopy air, and Trichoderma (27.27\%) and Mortierella (20.46\%) were dominant in the rhizosphere soils. Further analysis revealed that the cultivable endophytic fungi changed across geographic areas and showed a certain degree of variation in different tissues of $A$. adenophora. The cultivable fungi in mature and withered leaves fluctuated more than those in roots and stems. We also found that some cultivable endophytic fungi might undergo tissue-to-tissue migration and that the stem could be a transport tissue by which airborne fungi infect roots. Finally, we provided evidence that the fungal community within $A$. adenophora 
was partially shared with the contiguous environment. The data suggested a frequent interaction between fungi associated with $A$. adenophora and those in surrounding environments, reflecting a compromise driven by both functional requirements for plant growth and local environmental conditions.

Keywords: invasive plant, endophytic fungi, tissue specific, geographic variation, air fungi, soil fungi

\section{INTRODUCTION}

Biological invasion has seriously threatened ecosystem services and caused huge economic losses (Vilà et al., 2010). Understanding the invasive mechanism and controlling and eradicating harmful invasive species has been a great challenge in invasive biology. In the past few decades, many hypotheses, such as the enemy release (Keane and Crawley, 2002), local pathogen accumulation (Eppinga et al., 2006), and positive plant-soil feedback (van der Putten et al., 2007, 2013) hypotheses, have proposed that soil microbes are the key factors affecting the competitiveness of exotic plants. For example, Callaway et al. (2004) reported that soil microbes were involved in negative plant-soil feedback in the growth of Centaurea in the plant's native range but positive feedback outside of this range; Crocker et al. (2015) found that the pathogenic fungi Pythium accumulated in invaded soils and caused the death of many native plants while also indirectly enhancing the Phragmites australis invasion.

Relative to studies focused on rhizosphere soil fungi, few reports have characterized the endophytic fungi of invasive plants (Shipunov et al., 2008; Fischer and Rodriguez, 2013). However, all plants in nature appear to have symbioses with fungal endophytes (Rodriguez et al., 2009), and diverse fungi inhabiting plants can influence host performance, including disease resistance (Busby et al., 2016), stress tolerance (Rodriguez et al., 2008), and biomass accumulation (Mucciarelli et al., 2003). The high diversity of endophytes is indicative of their extremely complex and variable functional characteristics (Torres-Cortes et al., 2018). Endophytic fungi commonly have been categorized into two groups based on their manner of transmission: vertically transmitted endophytes (VTEs, e.g., Neotyphodium) that inhabit temperate grasses (Lolium) and are transmitted from the mother plant (Müller and Krauss, 2005) and horizontally transmitted endophytes (HTEs) transmitted mostly via spores from plant to plant (Arnold, 2007). Previous studies on native plants and crops indicated that fungal endophyte communities varied based on host genotypes (Emi and Kenji, 2013), plant tissues (Wearn et al., 2012), growth stages (Shi et al., 2016), and distribution areas (Geisen et al., 2017). However, most reports to date have addressed VTEs when exploring the endophytes of invasive plants (Rudgers et al., 2005); only very few studies have focused on the interaction between HTEs and invasive plants (Newcombe et al., 2009; Aschehoug et al., 2012). Although endophytic fungi have been proven to be a contributor to the competitiveness of exotic plants (Aschehoug et al., 2012), their variation in different tissues has not been investigated in detail during the geographical expansion of invasive plants.
In addition, it remains controversial whether endophytic fungi can grow systematically within plants. Jaber and Vidal (2010) verified that there was no systematic growth by inoculation experiments, in which the researchers could not isolate the corresponding strain from plant leaves after fungal inoculation of the roots. However, Hodgson et al. (2014) showed that systematic growth of endophytes was possible because many plant species harbored vertically transmitted fungi in seeds, and these endophytic fungi could also be recovered from the leaves. These vertically transmitted fungi have been verified to be mutualistic in promoting the invasion of temperate grasses (Rudgers et al., 2005). If horizontally transmitted endophytic fungi with positive effects can grow systematically in invasive plants, this may be an effective strategy to promote host competitiveness.

For decades, it has been demonstrated that plant species can modify the soil environment to shape rhizosphere microbes (Grayston et al., 1998), which in turn can provide feedback to promote plant growth (van der Heijden et al., 2008). Recently, some studies indicated that the phyllosphere microbes, either in living or the withered leaves, also had a strong negative feedback on plant growth (Whitaker et al., 2017), protection against pathogen damage (Ritpitakphong et al., 2016; Christian et al., 2017) and resistance to environmental stress (Saleem et al., 2017). These data highlighted the ecological importance of the microbes living in or around aboveground plant tissues. Moreover, although the enemy release hypothesis (ERH), which suggests that invasive hosts leave their enemies in their native range, partially explained some plant invasions (Keane and Crawley, 2002; Mitchell and Power, 2003), the accumulation of fungal pathogens after the introduction of exotic plants is unavoidable (Mitchell et al., 2010; Flory et al., 2013; Stricker et al., 2016). These accumulated fungal pathogens are predicted to affect neighboring native susceptible hosts if the pathogens are transmitted in the invaded ecosystem. Such dynamics are termed "spillover" when the pathogens are non-native and are introduced with the invasive plant and "spillback" when an invasive plant species hosts native pathogens (Flory et al., 2013). Previously, rare reports indicated that endophytes of invasive plants can act as local pathogens; for example, fungal endophytes, such as latent local pathogens, were isolated from the invasive plants Parthenium hysterophorus (Romero et al., 2001) and P. australis (Fischer and Rodriguez, 2013). Nonetheless, the current knowledge about the microbial community in the aboveground tissues of invasive plants as well as their association with the surrounding environment of the host is insufficient and limits the understanding of the role of fungi in plant invasion and risk evaluation. 
Ageratina adenophora (Sprengel) R. M. King and H. Robinson is a perennial herb of the Compositae family that is native to Central America but a noxious weed in Asia, Africa, Oceania, and Hawaii. Since the first record in China in the 1940s, the plant has now become widely distributed in six provinces in Southwest China and has continuously spread east- and north-ward at a rate of approximately $20 \mathrm{~km}$ per year (Wang and Wang, 2006). There is evidence that strong allelopathy (Inderjit et al., 2011) and high resource capture and use efficiency (Wang et al., 2013) promote its competitive advantages over native species. Recent studies have shown that $A$. adenophora frequently changes soil microbial communities to contribute to its invasion (Xu et al., 2012; Li et al., 2017; Zhu et al., 2017). In addition, Mei et al. (2014) indicated that the diversity and isolation frequency of foliar fungal endophytes have increased with time since the introduction of $A$. adenophora.

In this study, we sampled and characterized the cultivable endophytic fungi from the roots, stems, and leaves of A. adenophora from six invaded areas in Yunnan Province, China, to evaluate the distribution of these fungi in different tissues in response to the geographical expansion of $A$. adenophora. We also determined whether $A$. adenophora facilitated the systematic growth of endophytic fungi. Moreover, fungi in the withered leaves and from the surrounding air and soil environments were also investigated to explore the potential interactions between the fungal communities associated with A. adenophora and the surrounding environments.

\section{MATERIALS AND METHODS}

\section{Study Site}

In August 2015, during the period of the greatest vegetation growth, six A. adenophora populations were selected for sample collection in Yunnan Province (22.63-25.88 N, 99.31-102.37 E, 1171-2128 m), Southwest China (Supplementary Table S1). With increasing latitude, these six regions are XM, SM, NE, CY, $\mathrm{KM}$, and YL, in order. The bioclimatic data were obtained from the WorldClim database using ArcGIS v10.3 (Yahdjian et al., 2011) and showed that the annual average temperature in the study area was $15.1-19.1^{\circ} \mathrm{C}$ and the annual average precipitation was 1024-1530 $\mathrm{mm}$ (Figure 1). According to the invasion dynamics of A. adenophora in China (Wang and Wang, 2006), the six sampling regions in this study correspond with three invasion times: $>80$ years ago (XM, SM, NE, and CY), $\sim 40-50$ years ago $(\mathrm{KM})$, and $<20$ years ago (YL) (Figure 1 ). In addition to A. adenophora, some small shrubs, herbs, and few trees occur sporadically at the sample sites (Supplementary Table S1).

\section{Sample Collection}

In each region, we collected four types of plant samples (roots, stems, mature, and withered leaves) (Figure 2A) and four types of environmental samples (rhizosphere and non-rhizosphere soil, canopy and non-canopy air) (Figure 2B) for fungal isolation.

For plant samples, three mature and healthy A. adenophora individuals were randomly selected at each region, and the fourth pair of leaves, whole stems, and fibrous roots of each plant were collected and independently packaged in sterile polypropylene bags for the isolation of endophytic fungi (Figure 2A). Moreover, six naturally withered leaves of $A$. adenophora with relatively consistent degrees of wilting were also collected and packaged in a sterile polypropylene bag for the isolation of fungi (Figure 2A). A total of $72 \mathrm{~A}$. adenophora tissue samples were obtained from the six study areas, including 18 pairs of fully expanded leaves, and 18 stem tissue, 18 fibrous root, and 18 withered leaf samples. Fungi were isolated from all plant samples within $12 \mathrm{~h}$ after collection.

For environmental samples, approximately $500 \mathrm{~g}$ of soil was collected from the rhizosphere of $A$. adenophora and the surrounding environment in each region to isolate fungi from the rhizosphere and non-rhizosphere soil. Rhizosphere soils were collected from at least five plant individuals, and environmental soils were collected in the surrounding area approximately $10 \mathrm{~m}$ away from the area where $A$. adenophora was growing (Figure 2B). Both rhizosphere and environmental soils were collected at $5-15 \mathrm{~cm}$ underground. A total of 12 soil samples were obtained from six study areas, including six A. adenophora rhizosphere soil samples and six soil samples from the surrounding environment. Soil samples were taken back to the laboratory for temporary storage at $4^{\circ} \mathrm{C}$, and fungal isolation was carried out within 3 days. The isolation of airborne fungi was carried out using a natural trapping method to expose the culture medium to the $A$. adenophora canopy air or ambient air for $15 \mathrm{~min}$. The canopy air was considered the area with $>80 \%$ coverage of $A$. adenophora, while the ambient air was considered the area with no vegetation, $10 \mathrm{~m}$ away from the $A$. adenophora community (Figure 2B). The fungi in the canopy and ambient air were collected approximately $60 \mathrm{~cm}$ above the ground. A total of 12 air samples were obtained from six study areas, including six A. adenophora canopy air and six ambient air samples. The Petri dishes used to collect the fungal spores from the air were sealed with Parafilm and taken back to the laboratory for subsequent pure colony culture.

\section{Isolation and Purification of Fungi}

Both culture-dependent and culture-independent methods for fungal isolation are subject to inherent biases. For the former, the stronger competitors may emerge from tissues first, while the weaker competitors are excluded; for the latter, PCR bias may skew the representation of certain operational taxonomic units (OTUs) in the species pool (Christian et al., 2017). Although next-generation DNA sequencing has been increasingly applied to characterize fungal communities, the classification of OTUs based on sequence similarity commonly results in significant losses in taxonomic coverage (Yamamoto and Bibby, 2014), and such OTUs do not necessarily correspond to species (Ryberg, 2015). In addition, more importantly, at times fungal cultures cannot be obtained, thus stymieing the usage of these species for further ecological function experiments (Wearn et al., 2012). We thus applied culture methods in this study. Considering the preference of different fungi for different growth conditions, three types of media, namely, 2\% malt extract agar (MEA) (Christian et al., 2017), NS, and ZY, were used for the cultivable fungal isolation to cover more diverse fungi. NS medium contained $1 \mathrm{~g} \mathrm{KH}_{2} \mathrm{PO}_{4}, 0.5 \mathrm{~g} \mathrm{MgSO}_{4} \cdot 7 \mathrm{H}_{2} \mathrm{O}, 15 \mathrm{~g}$ peptone, $1 \mathrm{~g}$ PCNB (Terraclor 75\%), $0.3 \mathrm{~g}$ streptomycin sulfate, $0.12 \mathrm{~g}$ 


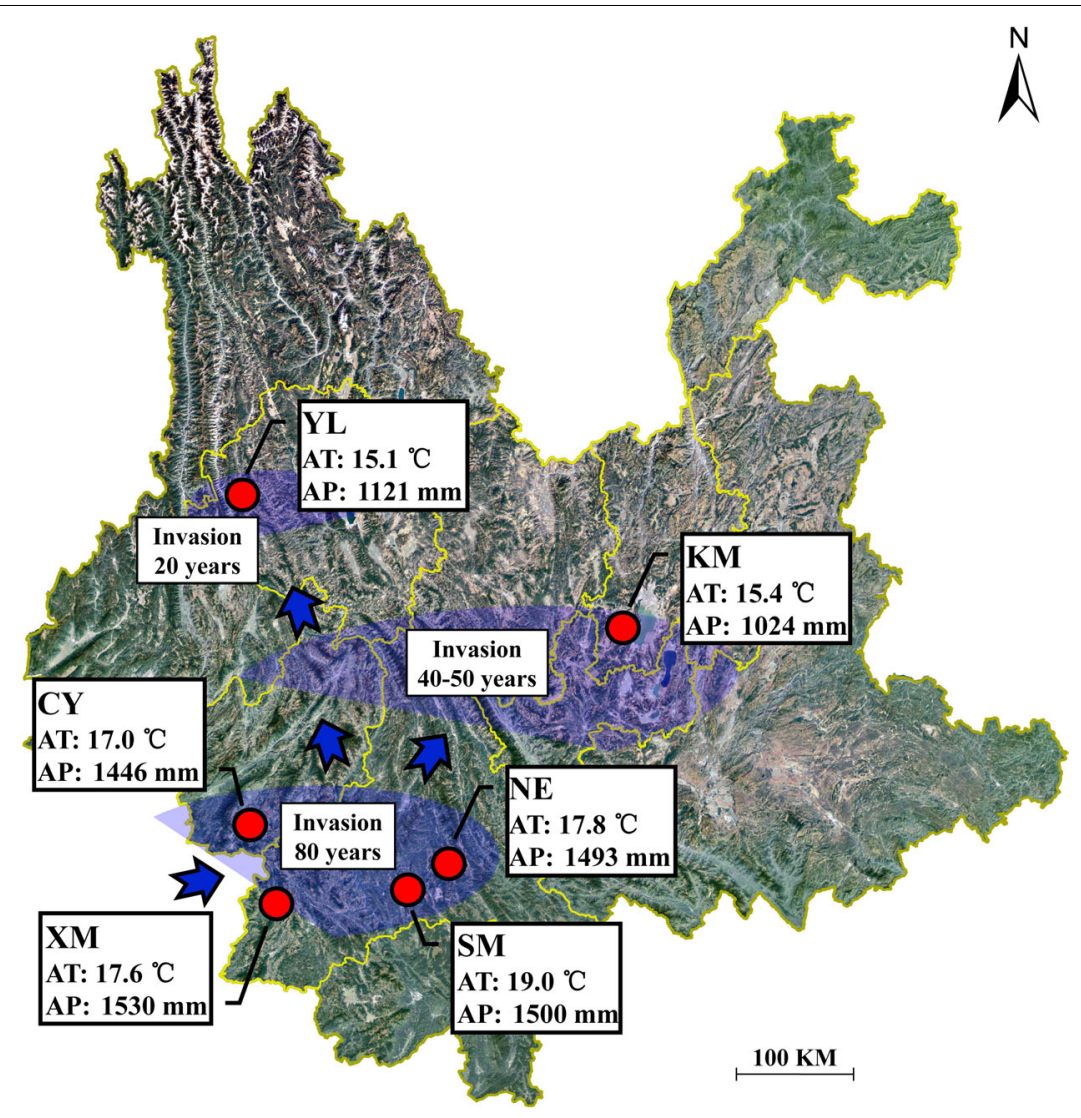

FIGURE 1 | Geographical location of the sampling sites in Yunnan Province, China. AT represents the annual average temperature; AP represents the annual average precipitation.

neomycin sulfate, and $20 \mathrm{~g}$ agar in $1000 \mathrm{ml}$ distilled water. ZY medium was made as follows: $200 \mathrm{~g}$ of $A$. adenophora healthy leaves was collected from the wild and cleaned and then boiled in $1000 \mathrm{ml}$ deionized water for approximately $30 \mathrm{~min}$; $15 \mathrm{~g}$ sucrose and $18 \mathrm{~g}$ agar were then added to the collected filtrate.

Endophytic fungi (roots, stems, and mature leaves) and fungi from withered leaves were isolated by placing surface sterilized tissue fragments on the culture medium (Figure 2A). First, plant samples were rinsed with tap water and then surface sterilized as follows: leaves (including mature and fallen) were submerged in $70 \%$ ethanol for $2 \mathrm{~min}, 0.5 \%$ sodium hypochlorite for $2 \mathrm{~min}$, and rinsed with sterile water six times; stems were submerged in $70 \%$ ethanol for $2 \mathrm{~min}, 0.5 \%$ sodium hypochlorite for $5 \mathrm{~min}, 70 \%$ ethanol for $1 \mathrm{~min}$, and rinsed with sterile water six times; roots were submerged in $70 \%$ ethanol for $5 \mathrm{~min}, 0.5 \%$ sodium hypochlorite for $5 \mathrm{~min}$, and rinsed with sterile water six times. The sterile water used for the last rinse was inoculated into potato dextrose agar (PDA, $1000 \mathrm{ml}$ distilled water containing $200 \mathrm{~g}$ potato, $20 \mathrm{~g}$ dextrose, and $20 \mathrm{~g}$ agar) medium to verify the surface sterilization. Subsequently, the same tissues collected at the same site were mixed and cut into pieces, with leaves and stems approximately $6 \mathrm{~mm}^{2}$ in size and roots approximately $0.2 \mathrm{~cm}$ in length. Sixteen pieces from each mixed sample were haphazardly selected and placed in a $10-\mathrm{cm}$-diameter Petri plate containing either $2 \%$ MEA, NS, or ZY medium. Soil fungi were isolated by preparing soil suspensions at a $10^{-3}$ dilution and uniformly plating the suspensions on $2 \%$ MEA, NS, or ZY medium (Figure 2B). Airborne fungi were isolated from the Petri dishes that collected airborne spores by the natural trapping method in the field (Figure 2B).

The culture procedures were repeated three times for each medium of the same sample, and 216 Petri plates (162 for endophytic fungi and 54 for withered leaf fungi) were used to isolate fungi from $A$. adenophora tissues, 108 Petri plates were used to isolate soil fungi, and 108 Petri plates were used to isolate air fungi. The Petri plates were sealed with Parafilm and incubated in a growth chamber in dark conditions at a constant temperature of $28^{\circ} \mathrm{C}$. Plates were monitored daily and the occurrence of fungal colonies was recorded as they emerged. The colonies on each plate were counted and classified into morphotypes as described previously (Glynou et al., 2016), and the representative strain of each morphotype was transferred to a new plate containing PDA for pure cultivation and for further colony morphological classification. In total, we counted 4066 colonies from three types of media and classified them into 1072 groups (Supplementary Table S2). Then, these representative fungal strains were subjected to molecular identification of ITS 

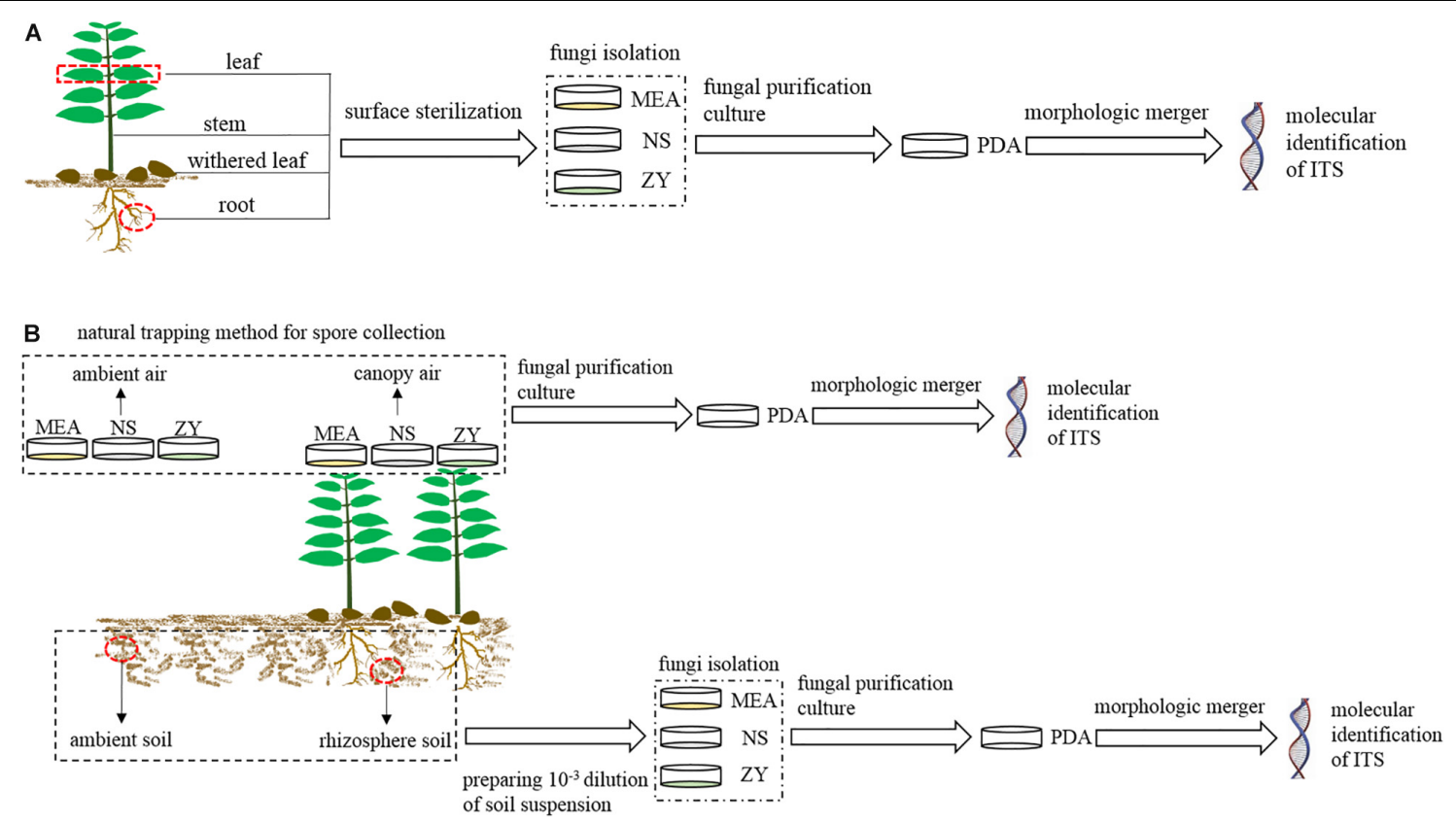

FIGURE 2 | Schematic workflow of the experimental process. MEA, NS, ZY, and PDA represent the four types of culture media. (A) Workflow for the isolation of fungi associated with plant; (B), workflow for the isolation of fungi from air and soil.

sequences. All representative strains were stored in the laboratory of Yunnan University for future experiments.

\section{Molecular Identification of Fungi}

Total genomic DNA was extracted from fungal mycelia using the CTAB method (Stewart and Via, 1993). The primers ITS4 and ITS5 were used to amplify the ITS region of the fungal DNA. Each $50 \mu \mathrm{l}$ PCR included $5 \mu \mathrm{l} 10 \times$ amplification buffer, $5 \mu \mathrm{l} \mathrm{dNTP}$ mixture, $1 \mu \mathrm{l}$ each primer $(10 \mu \mathrm{M}), 0.25 \mu \mathrm{l}$ Taq DNA polymerase,

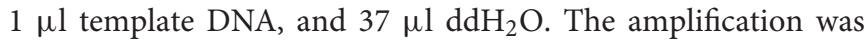
run in a Veriti ${ }^{\circledR}$ 96-Well Thermal Cycler (Applied Biosystems Inc., Foster City, CA, United States) [ $4 \mathrm{~min}$ at $94^{\circ} \mathrm{C}$, followed by 35 cycles $\left(1 \mathrm{~min}\right.$ at $94^{\circ} \mathrm{C}, 1 \mathrm{~min}$ at $54^{\circ} \mathrm{C}$, and $1 \mathrm{~min}$ at $72^{\circ} \mathrm{C}$ ), $10 \mathrm{~min}$ at $72^{\circ} \mathrm{C}$ ]. PCR products were tested by $1 \%$ gel electrophoresis and then sent to the Beijing Genomics Institute (BGI) for ITS sequencing.

Based on the GenBank database, sequence homology analysis, quality assessment, and correction were conducted. ClustalX 2.1 (Thompson et al., 1997) was used to cut out chimeric bases to make each sequence approximately $550 \mathrm{bp}$ in length. The Mothur program was used to identify the remaining sequences and group the consensus sequences into OTUs at unique and $97 \%$ sequence identity (Schloss et al., 2009). The nucleotide sequences reported in this study have been deposited in GenBank under the accession numbers MK303973-MK304430.

\section{Statistical Analyses}

All statistical analyses were performed at a level of $100 \%$ (unique) and 97\% ITS sequence identity. We pooled the colonies from the three plates of each medium, and the three types of medium were used as biological replicates for each sample because there were no significant differences in the community composition (Supplementary Figure S1), species diversity (Supplementary Figures S2A,B), and isolate abundance (Supplementary Figure S2C) among the three types of medium, with the exception that fungal community variation was significantly associated with the medium at $97 \%$ sequence identity (Supplementary Figure S1B; $F=2.2, p=0.002$ ) but only explained very little variation $[0.8 \%$ adjusted explained variation $(\mathrm{AEV})]$. Communities were defined as the sequenced fungal strains obtained from a given plant tissue, site, or environmental source.

Non-metric multidimensional scaling (NMDS) was used to visualize the similarity of fungal communities among plant tissues or environmental samples, and principal coordinate analysis (PCoA) was used to assess the spatial variation of endophytic and withered leaf fungal communities in different plant tissues during the geographical expansion of $A$. adenophora. At the unique sequence identity level, two outliers [NERS-NS and NE-AS-MEA; NE represents the sampling site, RS (rhizosphere soil) and AS (ambient soil) represent the source, and NS and MEA represent the culture medium; detailed in Supplementary Table S2] were eliminated in the NMDS analysis of the environmental samples. The correlation between fungal communities and the classified factors was tested by redundancy analysis (RDA). All distance matrices for community composition analyses were based on the Bray-Curtis dissimilarity index.

The Shannon diversity index was calculated for fungi from both plant tissue and the environment. ANOVA was used to compare the diversity and abundance of fungi (containing endophytic and withered leaf fungi) across plant tissues and 
geographical sites. Assumptions of normality were tested by Kolmogorov-Smirnov test, and the assumptions were met. Post hoc comparisons were performed using Duncan's tests for equal variance and Dunnett's T3 tests for unequal variance. Linear regression was used to analyze the relationship between the Shannon diversity index or average abundance and latitude. Mann-Whitney $U$ non-parametric tests were used to compare the diversity and average abundance of fungi from different environmental sources. Fungal relative abundance was calculated to analyze the relationship between plant tissue and environmental fungi.

Multivariate analyses were performed using CANOCO, version 5.0 (Ter Braak and Šmilauer, 2012), and all other analyses were executed using SPSS version 22.0 (SPSS Inc., Chicago, IL, United States). Visualization of diversity and abundance data were realized with GraphPad Prism 7 (GraphPad Software Inc., San Diego, CA, United States).

\section{RESULTS}

\section{Phylogenetic Analysis}

A total of 4066 cultivable isolates were counted and investigated, including 1641 endophytic fungi, 233 withered leaf fungi, 1255 air fungi, and 937 soil fungi. Based on their colony morphologies, these fungi were first classified into 1072 groups, and the representative strains from each group were sequenced into the ITS gene and then divided into 458 and 201 OTUs at unique and 97\% sequence identity, respectively (Supplementary Table S3). These isolates were placed into four phyla, including Ascomycota (94.20\%), Basidiomycota (2.71\%), Mortierellomycota (3.03\%), and Mucoromycota (0.07\%). The isolates in Ascomycota were further divided into five classes, including Dothideomycetes (34.07\%), Eurotiomycetes (5.93\%), Leotiomycetes (0.47\%), Pezizomycetes $(0.13 \%)$, and Sordariomycetes (59.37\%). The dominant genera of cultivable endophytic fungi were Colletotrichum (34.61\%), Diaporthe (17.24\%), Allophoma (8.03\%), and Fusarium (4.44\%). Colletotrichum and Diaporthe were primarily isolated from mature leaves, Allophoma from stems, and Fusarium from roots. The dominant genera differed in the withered leaves and were represented by Alternaria (21.46\%), Allophoma (19.31\%), Xylaria (18.45\%), and Didymella (18.03\%). In addition, Cladosporium (22.86\%), Trichoderma (14.27\%), and Epicoccum (9.83\%) were the most abundant cultivable fungi in the canopy air, but Trichoderma (27.27\%) and Mortierella (20.46\%) were dominant in the rhizosphere soil.

\section{Tissue Specificity in Cultivable Fungal Communities}

The community composition (Figures 3A,C) of cultivable endophytic fungi in $A$. adenophora showed tissue specificity, while there was systematic growth of a few strains in plants (Figures 3B,D). However, there was no consistent trend for the OTUs at unique and $97 \%$ sequence identity. Although there was a significant correlation between plant tissue and fungal community variation both at the unique $[F=2.8$; $p=0.002 ; 3.8 \%$ explained variation $(\mathrm{EV}), 2.5 \% \mathrm{AEV}]$ and $97 \%$ $(F=5.1 ; p=0.002 ; 6.7 \% \mathrm{EV}, 5.4 \% \mathrm{AEV})$ sequence identity levels, community variations between different tissues were more distinct at the 97\% level (Figure 3C), while the unique sequences only showed such variation between above- and belowground tissues (Figure 3A). The closeness of plant tissues appears to impact the composition of the fungal community, i.e., the endophytic community composition between roots, stems, and leaves was more similar (Figures 3A,C), and the number of identical fungi between stems and roots was higher than that between leaves and roots (Figures 3B,D). In addition, Shannon diversity (Figures 4A,B) and average abundance (Figure 4C) showed variation among different tissues, among which mature leaves had the highest levels, while the withered leaves had the lowest levels.

\section{Geographical Variation in Cultivable Fungal Communities}

Cultivable fungal communities in plant tissues varied among geographic sites (Figures 5, 6) at either the unique or 97\% sequence identity level. The six sampling sites could be divided into three groups of low (including XM, SM, NE, and CY, latitude from 22.63 to 23.22), middle (KM, latitude 24.54), and high (YL, latitude 25.88) latitudes. RDA showed that the latitude was an important factor for explaining the differences in composition in cultivable fungal communities among roots (Figure 5A: $F=1.7$; $p=0.006 ; 9.8 \% \mathrm{EV}, 4.1 \%$ AEV; Figure 5E: $F=2.9 ; p=0.002 ; 15.4 \%$ $\mathrm{EV}, 10.1 \% \mathrm{AEV}$ ), leaves (Figure 5C: $F=3.0 ; p=0.002 ; 16.0 \% \mathrm{EV}$, $10.7 \%$ AEV; Figure 5G: $F=3.6 ; p=0.002 ; 18.3 \% \mathrm{EV}, 13.2 \% \mathrm{AEV})$, and withered leaves (Figure 5D: $F=1.7 ; p=0.044 ; 9.5 \% \mathrm{EV}, 3.9 \%$ AEV; Figure 5H: $F=2.8 ; p=0.006 ; 14.7 \% \mathrm{EV}, 9.4 \% \mathrm{AEV})$ but not among stems (Figure 5B: $F=1.3 ; p=0.118 ; 7.5 \% \mathrm{EV}, 1.7 \% \mathrm{AEV}$; Figure 5F: $F=1.4 ; p=0.172 ; 8.2 \% \mathrm{EV}, 2.5 \% \mathrm{AEV})$.

Similar to the community composition, except for the cultivable endophytic fungi of the stems (Figure 6B), the Shannon diversity index and average abundance in the other three plant tissues were significantly different among the sampling sites (Figures 6A,C,D), but the same linear relationship with latitude was not observed (Figure 7). For example, the latitude positively correlated with the diversity of the leaf fungi (Figure 7C) but negatively correlated with the diversity of the withered leaf fungi (Figure 7D) and with the abundance of the leaf fungi (Figure 7C).

\section{Association of Cultivable Fungal Communities With the Surrounding Environments}

The cultivable fungal community composition was significantly different between air and soil at both unique (Figure 8A, $F=4.1$; $p=0.002 ; 5.7 \% \mathrm{EV}, 4.3 \% \mathrm{AEV}$ ) and $97 \%$ (Figure 8C, $F=7.4$; $p=0.002 ; 9.6 \% \mathrm{EV}, 8.3 \% \mathrm{AEV}$ ) sequence identity levels, with a few shared strains in both environments (Figures 8B,D). However, A. adenophora invasion only marginally changed the composition (Figures $\mathbf{8 A}, \mathbf{C}$ ), Shannon diversity index (Figures 9A,B), and average abundance (Figure 9C) of cultivable fungal communities, either in canopy air or rhizosphere soils. 

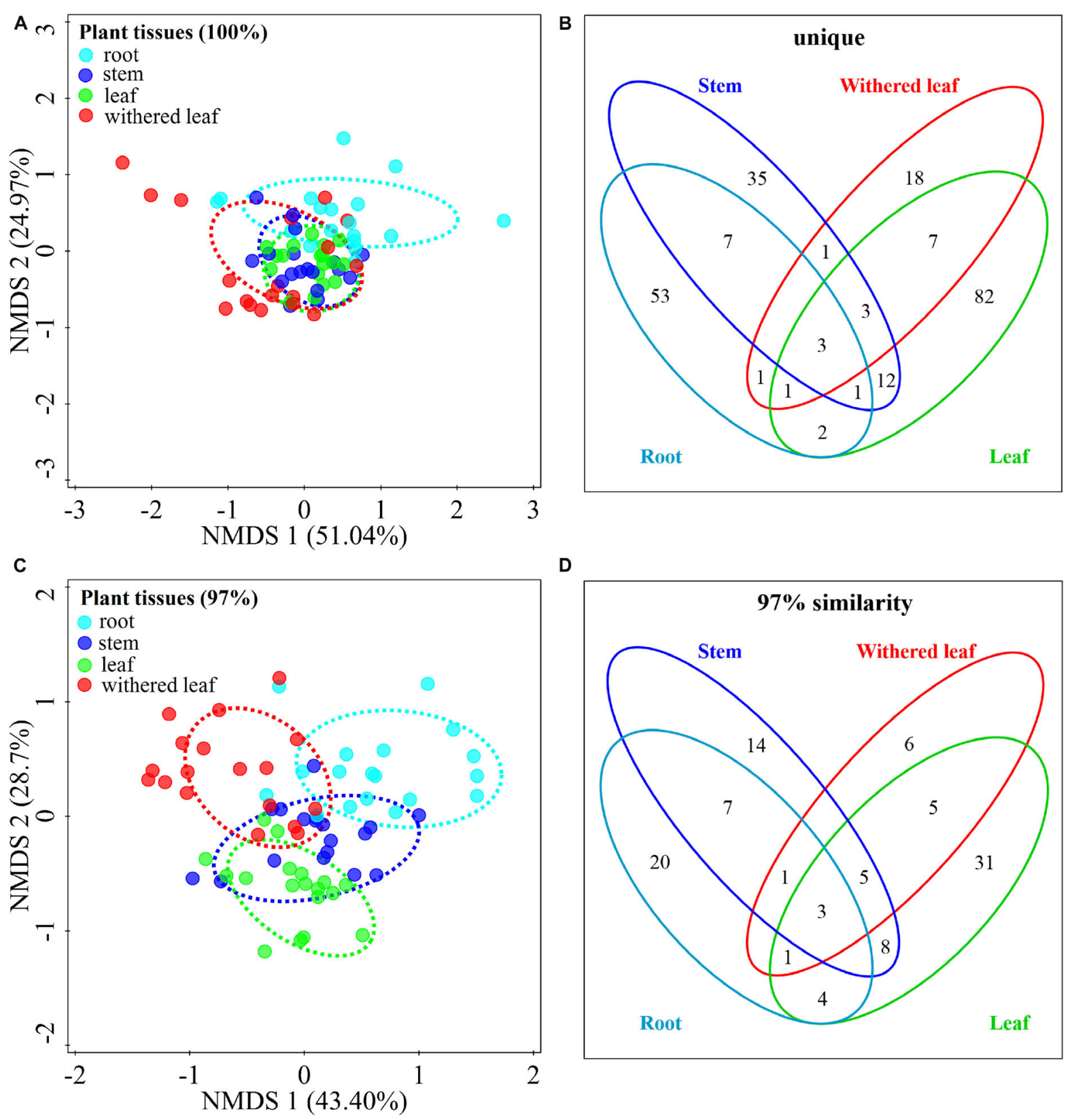

D

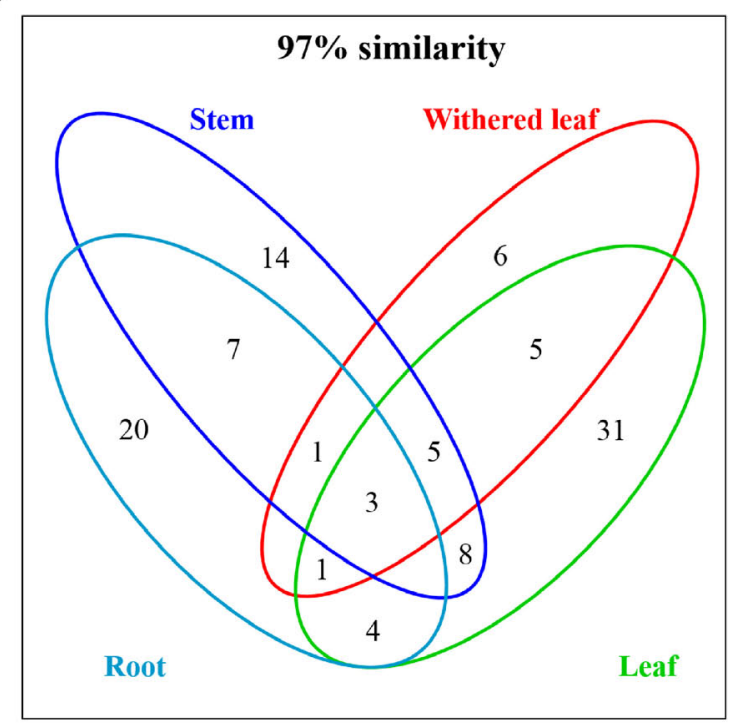

FIGURE 3 | Tissue specificity of cultivable fungal communities in A. adenophora. Non-metric multidimensional scaling (NMDS) analysis shows the similarity among cultivable fungal communities (points) [A (unique), stress $=0.083$; C $(97 \%)$, stress $=0.112$ ], and the Venn diagram shows the amount of the same or different OTUs among plant tissues [B (unique), D (97\%)]. Percentages of total variation explained by the NMDS axes are given in parentheses.

RDA showed that the cultivable fungal community was only significantly different between the rhizosphere and the ambient soils at $97 \%$ sequence identity $(F=1.7 ; p=0.034 ; 4.7 \%$ $\mathrm{EV}, 1.8 \% \mathrm{AEV})$, while other cases were not significantly different [air (unique): $F=1.1 ; p=0.282 ; 3.0 \% \mathrm{EV}, 0.2 \%$ AEV; air (97\%): $F=0.9 ; p=0.612 ; 2.5 \% \mathrm{EV}, 0.0 \% \mathrm{AEV}$; soil (unique): $F=1.4 ; p=0.07 ; 4.1 \% \mathrm{EV}, 1.1 \% \mathrm{AEV}$. Nonetheless, A. adenophora caused certain fungal fluctuations in surrounding environments at the genus level (Figures 9D,E); for example, Cladosporium, Trichoderma, Allophoma, and Gibberella were much more abundant in canopy than in ambient air (Figure 9D), and Trichoderma and Mortierella were three and six times higher in rhizosphere soil than in ambient soil (Figure 9E).

The cultivable fungi in aboveground tissues (stems, leaves, and whithered leaves) were closely related to those in contiguous environments, especially at 97\% sequence identity (Figure 10 and Supplementary Figure S3). For example, foliar endophytic fungi shared $14.60 \%$ OTUs with canopy air but only $1.01 \%$ with rhizosphere soils at a unique level (Figure 10C), and these 

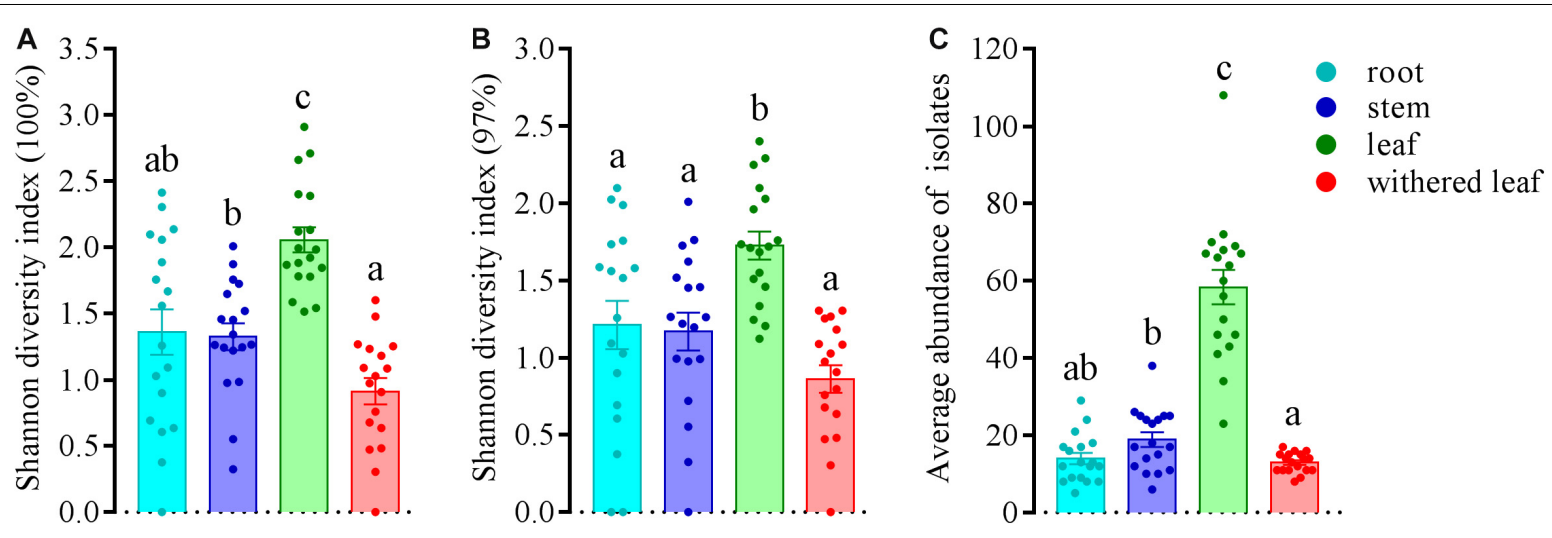

FIGURE 4 | Variation in Shannon diversity index values at unique (A) and 97\% sequence identity levels (B) and average abundance (C) in cultivable fungal communities among different tissues of $A$. adenophora. The Kolmogorov-Smirnov normality test was satisfied. Dunnett's T3 test was used for multiple comparisons. Different lowercase letters indicate significant differences $(p<0.05)$. Error bars depict the standard errors.

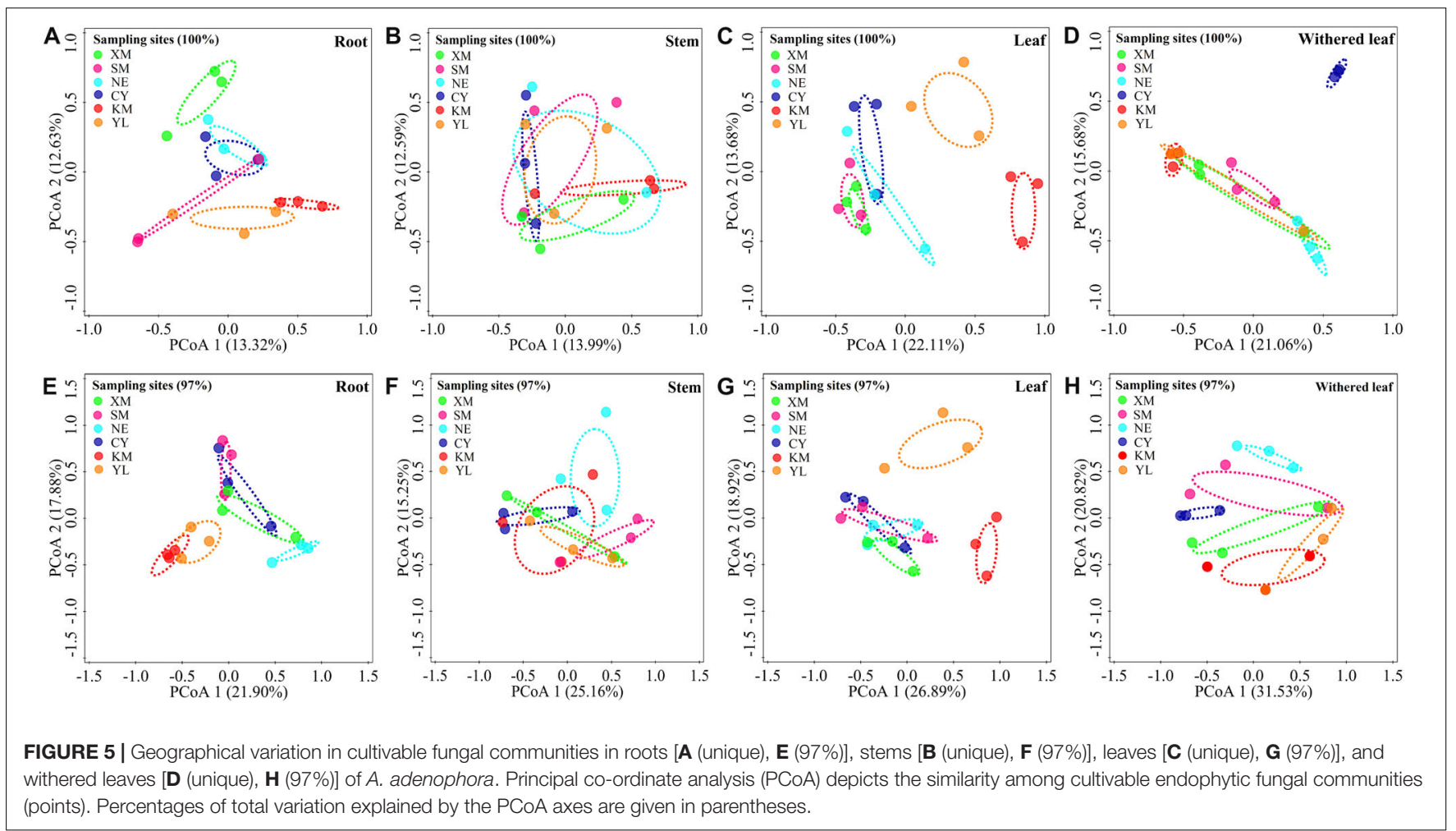

two percentages increased to 41.86 and $15.66 \%$, respectively, at $97 \%$ sequence identity (Figure 10G). Similarly, the withered leaves shared $9.93 \%$ of cultivable fungi with canopy air but no sharing occurred with rhizosphere soil fungi at the unique identity level (Figure 10D). Interestingly, both roots and stems shared larger proportion of fungi with canopy air than with rhizosphere soils (Figures 10A,B,E,F). In total, the proportion of shared fungi was larger when comparing plant tissues than when comparing plant tissue with environments, and when comparing plant tissues with canopy air than comparing plant tissues with soils (Supplementary Figure S3). A few fungi in the aboveground tissues, which were not isolated from the contagious canopy air, were shared with soils (Figure 10 and Supplementary Figure S3).

\section{DISCUSSION}

The horizontally transmitted endophytic fungi usually differ among plant species in a certain habitat (Emi and Kenji, 2013) and vary among different tissues within an individual plant (Wearn et al., 2012). In this study, the cultivable endophytic fungal community of $A$. adenophora showed obvious tissue specificity (Figures 3, 4), consistent with most previous results 


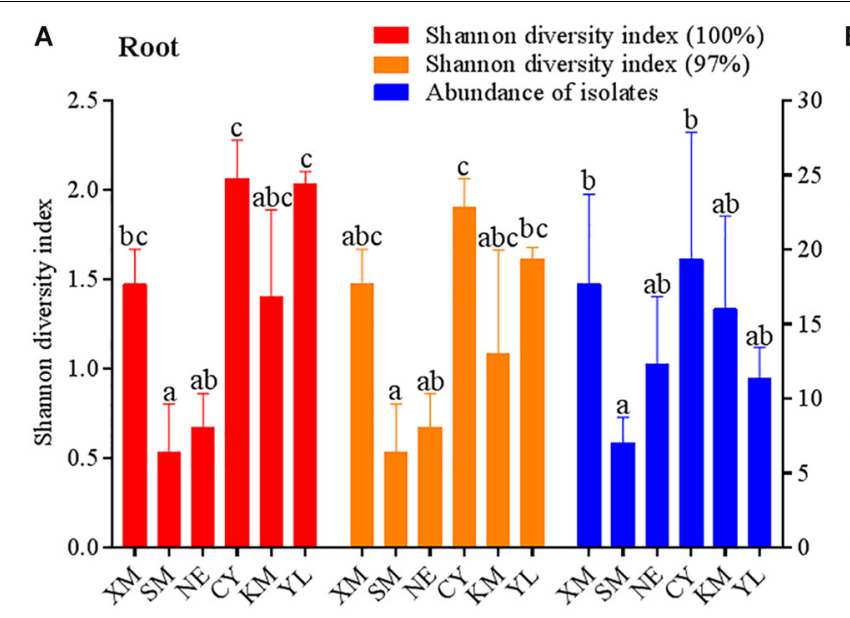

B Stem

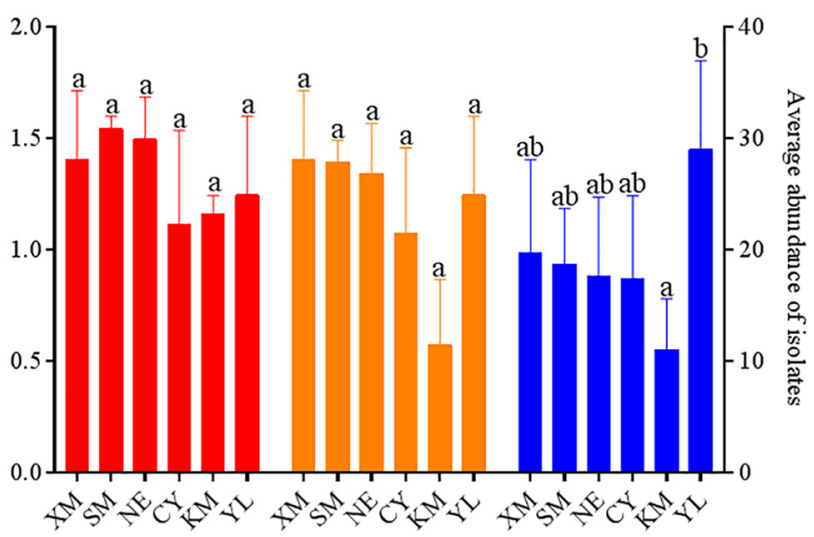

C

D Withered leaf

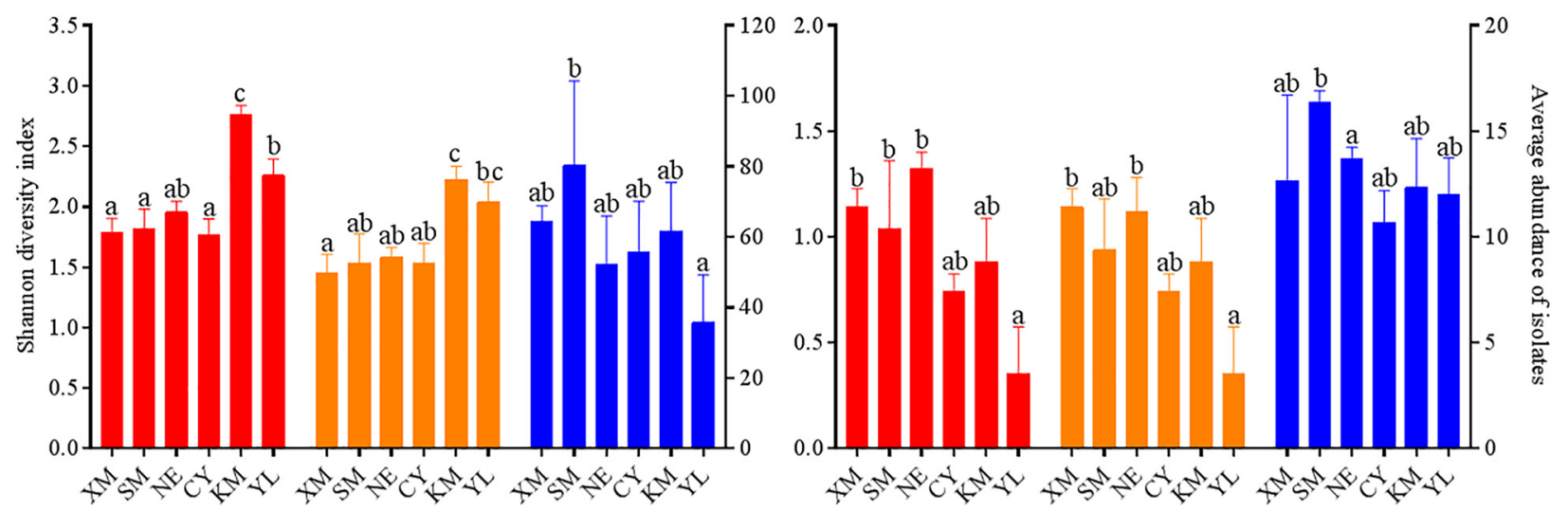

FIGURE 6 | Geographical variation in Shannon diversity index values and average abundance of cultivable fungal communities in different tissues (A, roots; B, stems; C, leaves; $\mathbf{D}$, withered leaves) of $A$. adenophora. The Kolmogorov-Smirnov normality test was satisfied. Dunnett's T3 test was used to compare the geographical variation in the average fungal abundance of the withered leaves, and Duncan's test was used for all other multiple comparisons. Different lowercase letters indicate significant differences $(p<0.05)$. Error bars depict the standard errors.

(Wearn et al., 2012; Yan et al., 2015; Geisen et al., 2017). However, our study further detailed that the cultivable endophytic fungi, as well as the withered leaf cultivable fungi, changed with the geographic expansion of $A$. adenophora and showed a certain degree of variation in different tissues (Figures 5, 6). Relative to the roots and stems, the mature and withered leaves showed more significant fluctuations of the cultivable fungi with geographic latitude (Figure 7). In a given tissue, the change pattern was also different for the investigated fungal parameter. For example, the fungal diversity was positively correlated but the abundance was negatively correlated with latitude (Figure 7C). These change patterns may be related to the selectivity of functional requirements in the assembly of endophytic fungi in plant tissues (Torres-Cortes et al., 2018) under different geographic backgrounds (Martiny et al., 2006; Rodriguez et al., 2009; Yokoya et al., 2017). In general, fungal endophyte communities vary across latitudinal gradients (Arnold and Lutzoni, 2007). The endophytic fungi of exotic plants, even with vertical transmission, also change with the expansion of exotic plants to high latitudes (Geisen et al., 2017).
It is very complex to decipher the factors influencing the fungal change pattern along with the northward invasion of A. adenophora; however, more fluctuations were observed in fungi inhabiting leaf tissues than those inhabiting roots and stems (Figure 7), suggesting that leaves may face strong fluctuations in environmental temperature stress during $A$. adenophora expansion (Figure 1). Similarly, Kazenel et al. (2019) also indicated that leaf fungi varied more strongly with altitude or warming than root fungi, suggesting that leaf symbioses may be particularly susceptible to disruption under climate change, perhaps because they are less buffered against air temperatures than belowground fungi.

Lodge et al. (1996) and Rodriguez et al. (2009) described fungal endophyte species as a mosaic of infections in a leaf, implying that plant infection with endophytes was limited by the random dynamics of microbial resources in the environment as well as the selective effects of plant species or plant tissues. Because Yan et al. (2015) demonstrated that there was very little evidence for any systematic growth of foliar fungal endophytes within an individual plant, and the main driving 
$-\Theta$. Shannon diversity index $(100 \%)-\Theta$. Shannon diversity index $(97 \%)-\Theta \cdot$ Abundance of isolates

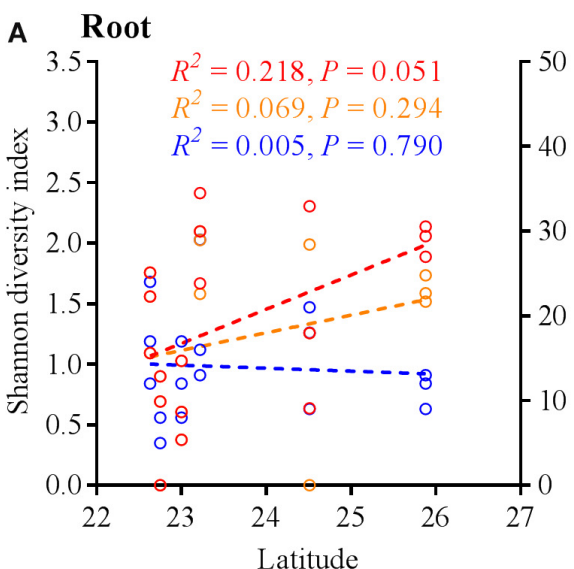

C

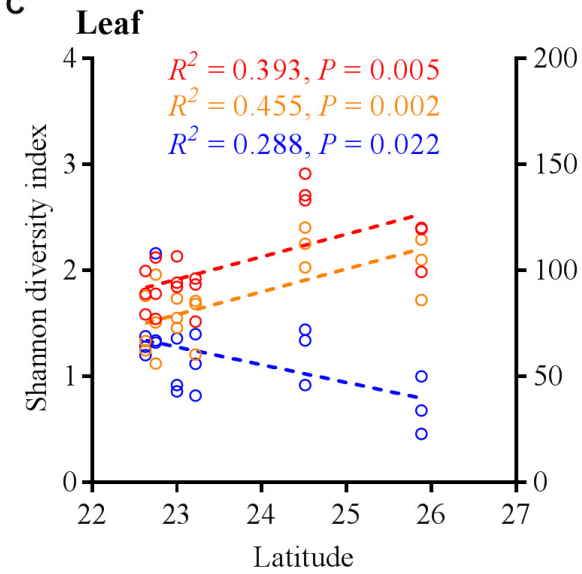

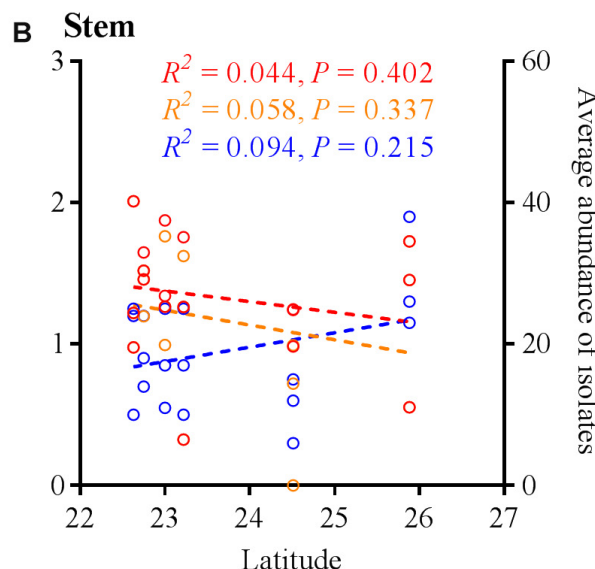

D Withered leaf

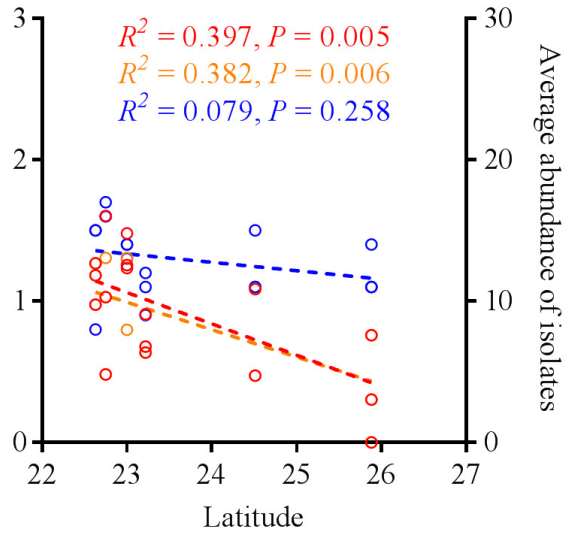

FIGURE 7 | Linear regression of latitudes with Shannon diversity index values and average abundance of cultivable fungi in A. adenophora different tissues (A, roots; B, stems; C, leaves; D, withered leaves).

process behind the assembly of foliar fungal endophytes was random. We found that the cultivable fungi in plant tissues were shared with those from both canopy air and rhizosphere soil, representing the important role of random environmental dynamics in the composition of cultivable fungal communities in $A$. adenophora. This role was also supported by the greater number of fluctuations in fungi inhabiting leaf tissues than in those inhabiting roots and stems (Figure 7). Moreover, there was a higher percentage of shared fungi in aboveground tissues and canopy air than in roots and rhizosphere soils (Figure 10 and Supplementary Figure S3), indicating that the environmental inoculation sources played a more important role in the fungal assembly of aboveground parts than in that of the belowground parts. Interestingly, even the assemblage of fungal communities in plant tissues may be a compromise driven by both functional requirements for plant growth (TorresCortes et al., 2018) and local environmental conditions, e.g., the temperature (Campisano et al., 2017); the former may weight out the latter because we found that the fungal similarity within tissues was much higher than that between tissues on a relatively large geographical scale (Figure 3).
Within a host, some studies have demonstrated endophytic bacterial migration through tissues (Chi et al., 2005; Tharek et al., 2011). For example, Martí et al. (1999) demonstrated that Agrobacterium tumefaciens was recovered from both roots and crowns 3 months after inoculation of rose plant stems. There has been no report about horizontally transmitted fungal endophyte migration in exotic plants. We found a large number of shared fungi between rhizosphere soil, plant tissue, and canopy air (Figure 10 and Supplementary Figure S3); the cultivable fungal community composition was related to the tissue connection; that is, both the similarity and the number of the shared fungi between roots and stems were higher than those between roots and leaves (Figure 3 and Supplementary Figure S3). Again, the portion of shared root endophytic fungi was explained not only by those from the rhizosphere soil but also by a high proportion of those from air fungi (Figures 10A,E and Supplementary Figure S3). We also isolated a small proportion of soil fungi in the mature leaves (Figures 10C,G and Supplementary Figure S3). These facts indirectly indicated that some endophytic fungi of $A$. adenophora might undergo tissue-to-tissue migration and that the stem could be a transport 

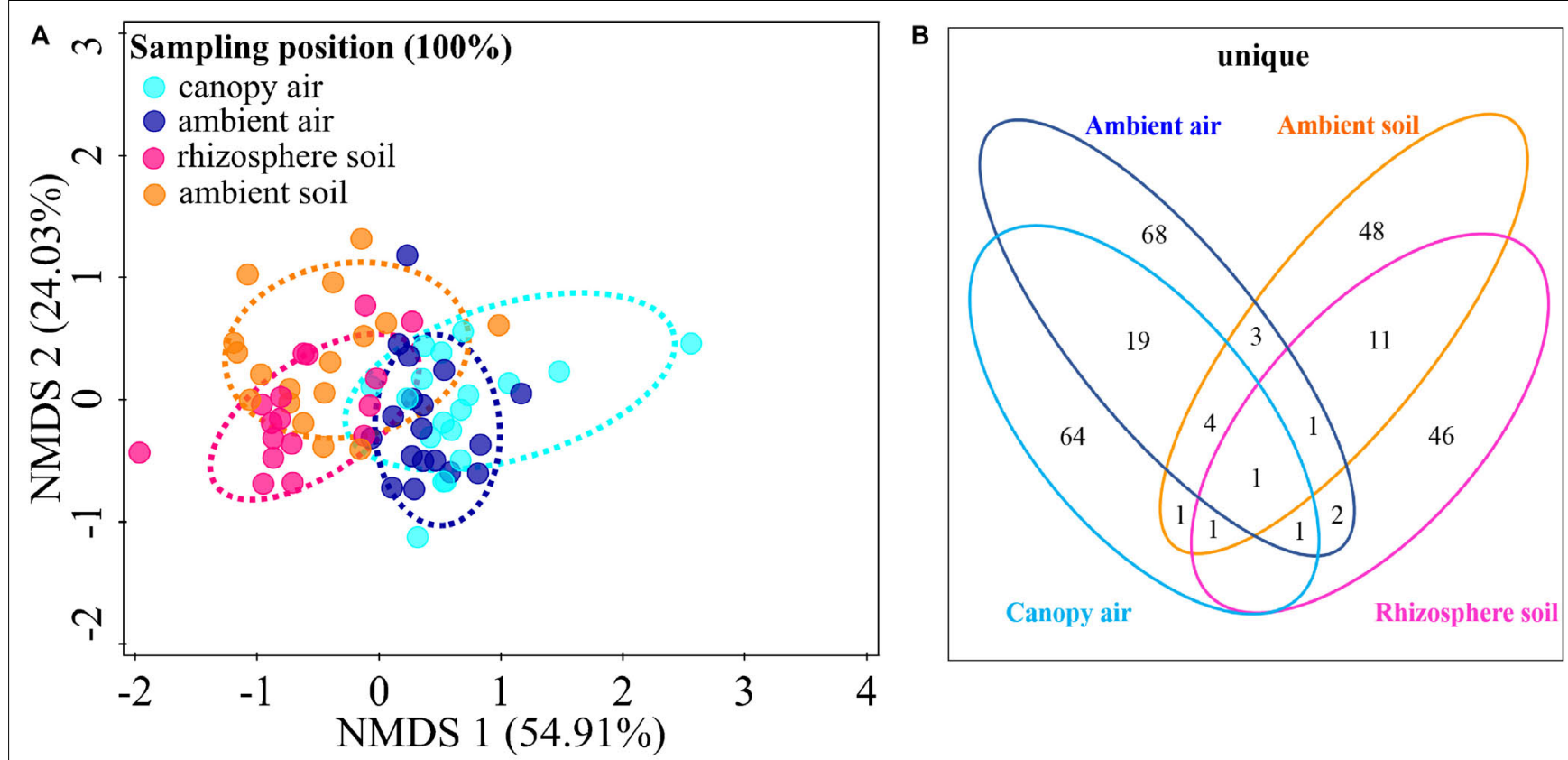

C

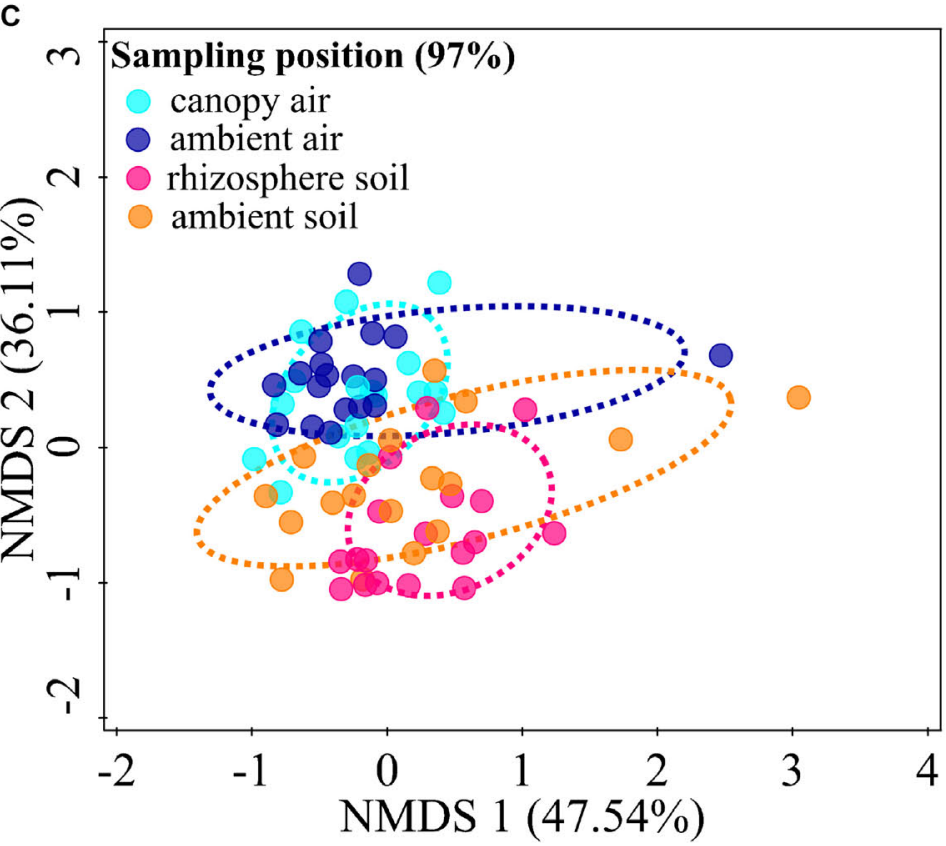

D

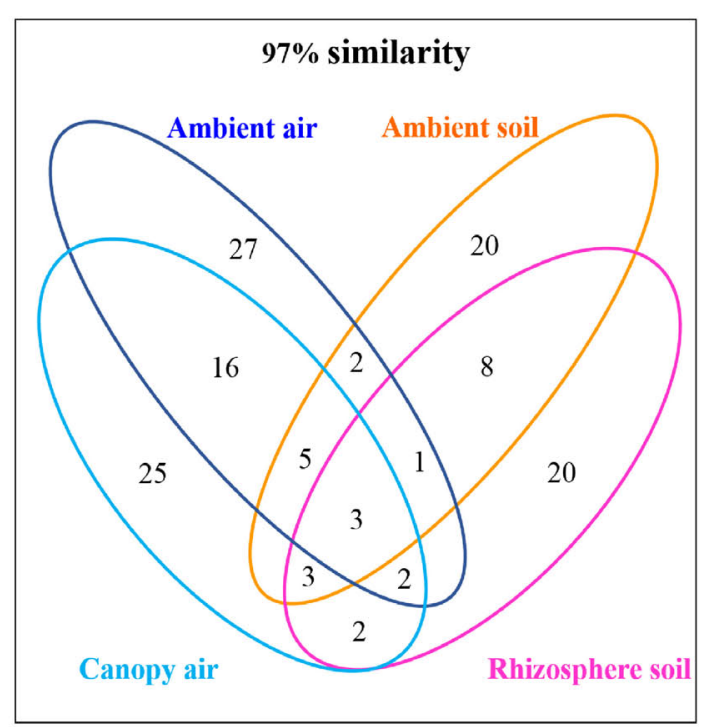

FIGURE 8 | Effects of $A$. adenophora invasion on the cultivable fungal communities in air and soil. Non-metric multidimensional scaling (NMDS) analysis shows the similarity among cultivable fungal communities (points) [A (unique), stress $=0.052 ; \mathbf{C}(97 \%)$, stress $=0.102]$, and the Venn diagram shows the amount of the same or different OTUs among environment samples [B (unique), D (97\%)]. There were two outlier samples [NE-RS-NS and NE-AS-MEA; NE represents the sampling site, RS (rhizosphere soil) and AS (ambient soil) represent the source, and NS and MEA represent the culture medium. See Supplementary Table S2 for details.] at the unique sequence identity level (A). To better visualize the primary data, the NMDS analysis shown in panel A does not take these two outliers into account. Percentages of total variation explained by the NMDS axes are given in parentheses.

tissue for fungal travel from the air to leaves and then to the roots or vice versa. These findings thus introduce an interesting topic, i.e., the study of the transport of fungi in stems for understanding the interaction of endophytic fungi with the host as well as the surrounding environment including the soil and canopy air.
Multiple studies have shown significant impacts of invasive plant populations on soil microbial communities (Xu et al., 2012; Li et al., 2017; Malinich et al., 2017); however, such an effect on airborne microbes has received no attention. In fact, plants contribute microbes to the air around them (Lymperopoulou et al., 2016). In this study, there was 


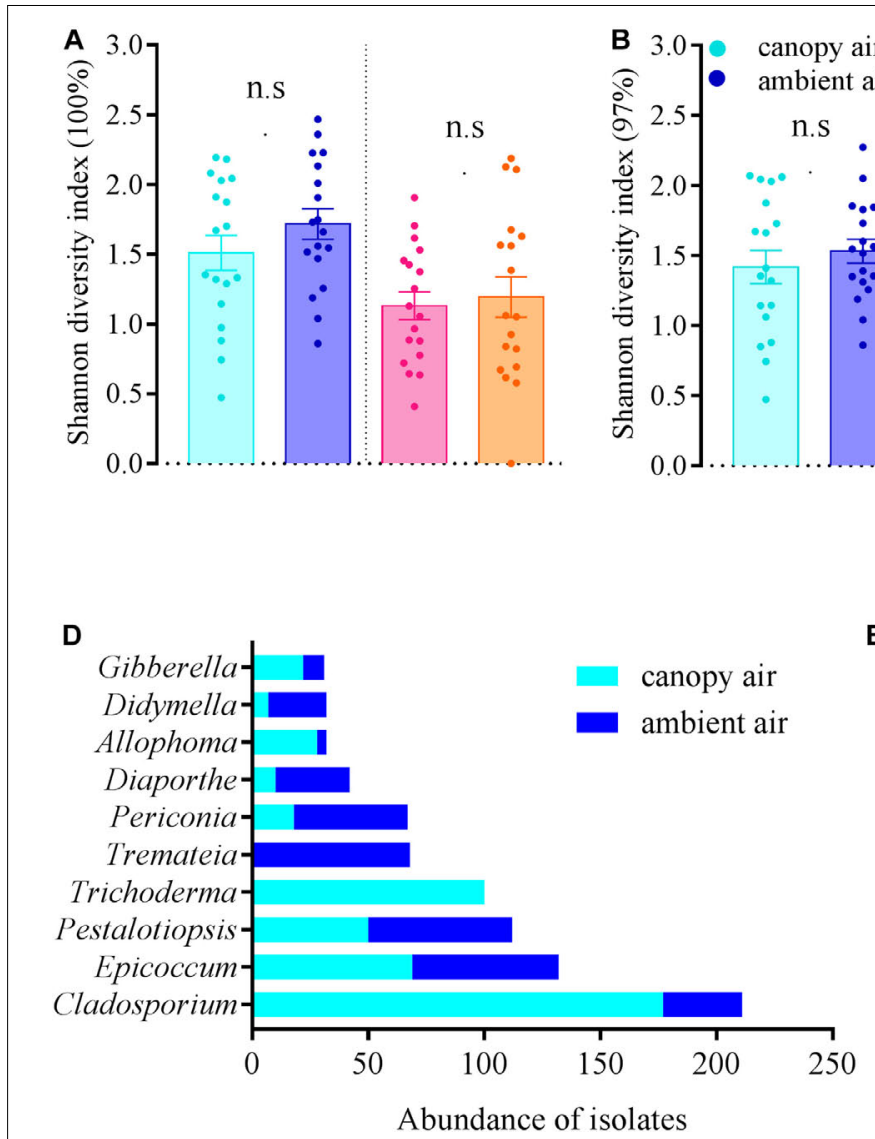

$\mathbf{E}$

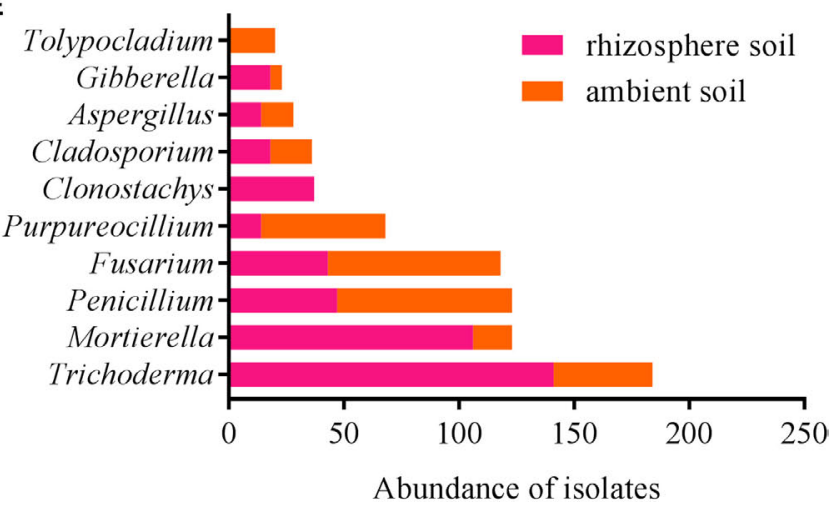

FIGURE 9 | Effects of $A$. adenophora on Shannon diversity index values [A (unique), B (97\%)], community average abundance (C), and total abundance of dominant cultivable fungal genera (D,E) in air and soil. Non-parametric Mann-Whitney U-test was used for the test of two independent samples (canopy air vs. ambient air, rhizosphere soil vs. ambient soil), and n.s. indicates no significant difference ( $p>0.05)$. Error bars depict the standard errors.

no significant effect of $A$. adenophora on fungi at the community level, both in rhizosphere soil and canopy air (Figures 8A,C, 9A-C); however, A. adenophora changed the dominant genera (Supplementary Table S3) and the total abundance of certain strains (Figures 9D,E). The data indicated that certain fungal taxa, e.g., Cladosporium, Trichoderma, Allophoma, and Gibberella, may have been released into the air from the leaf surface by $A$. adenophora. In recent years, studies on the interaction between the phyllosphere microbiome and plants have emphasized the importance of microbes inhabiting aboveground tissues in ecology (Ritpitakphong et al., 2016; Christian et al., 2017; Saleem et al., 2017; Whitaker et al., 2017). Therefore, it is both important and interesting to explore the potential ecological effects of certain fungi released into the air by $A$. adenophora, e.g., these fungi, if they are local pathogens, may increase the risk of disease infection in neighboring plants (also see the section "Discussion").

Currently, the interactions between endophytic fungi and their hosts have been considered diverse, and evaluating their ecological consequences is complex (Newsham, 2011). Interestingly, it has been recently reported that many fungi, such as Colletotrichum, Fusarium, and Verticillium, can not only inhabit some plant species as endophytes but also have pathogenic effects on other plant species (Arnold, 2007). For example, Colletotrichum magna, a pathogen of Cucurbitaceae plants, often exists in other non-Cucurbitaceae plants as an endophyte (Kogel et al., 2006). Many crop pathogens also frequently lurk in other weeds in an endogenous form (Photita et al., 2004). Previously, fungal endophytes, as latent local pathogens, were isolated from the invasive plants P. hysterophorus (Romero et al., 2001) and P. australis (Fischer and Rodriguez, 2013). The possible enrichment of endophytic fungi that may act as local pathogens by invasive plants can undoubtedly serve as a weapon to indirectly promote plant invasion. The most abundant endophytic fungi isolated from A. adenophora were Colletotrichum (Supplementary Table S1), many of which have been reported as generalist pathogens (O'Connell et al., 2012), accounting for $>50 \%$ of the foliar endophytic fungi. Therefore, it is worth evaluating whether the direct and indirect effects of the spillback of accumulated fungi on neighboring plants finally become a competitive advantage for $A$. adenophora. In addition, compared with the fungi in ambient air and soil, more abundant Trichoderma were isolated in the rhizosphere soil and canopy air of $A$. adenophora (Supplementary Table S3 and Figures 9D,E). Since at least the 1920s, Trichoderma 

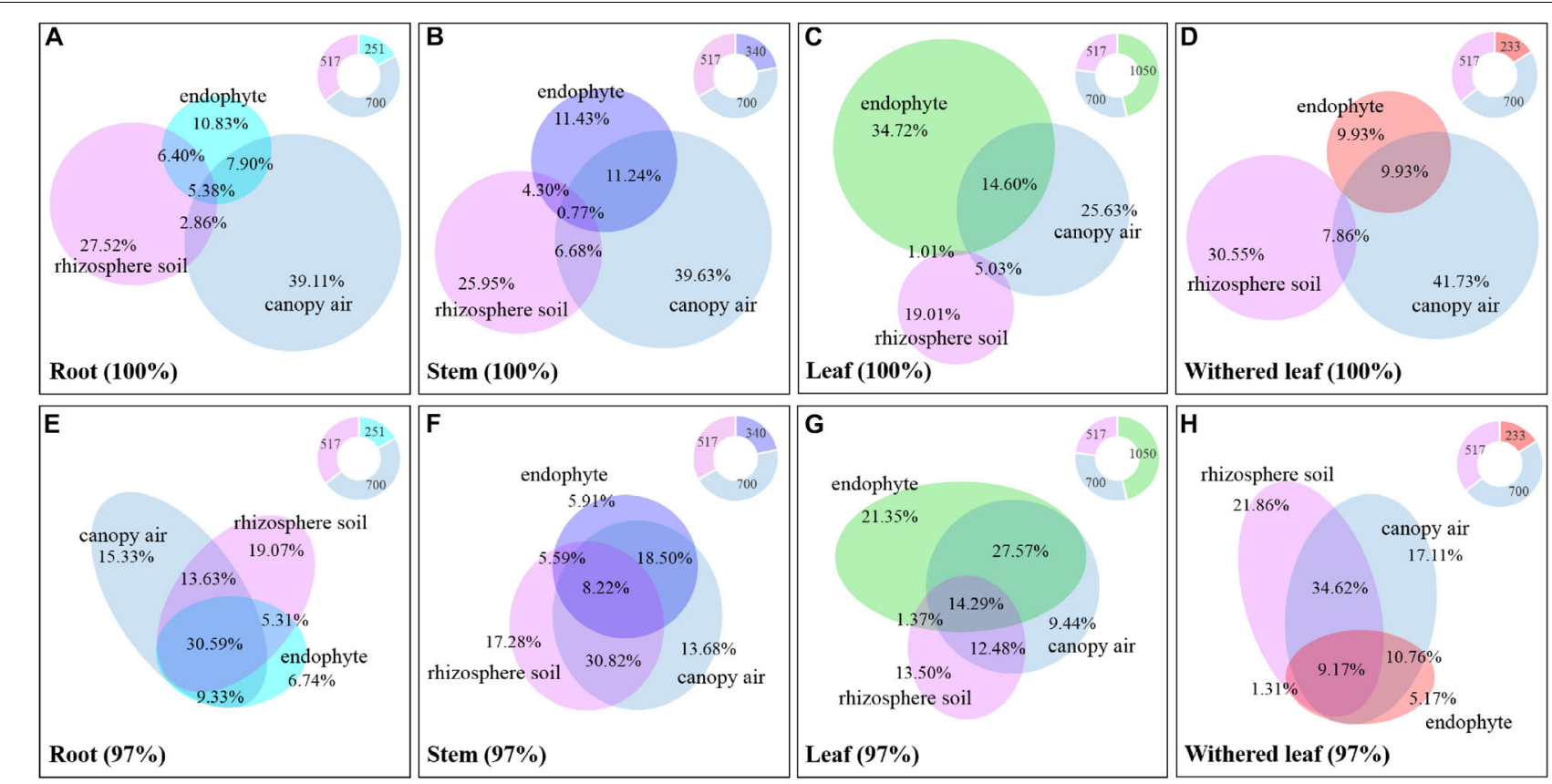

FIGURE 10 | Relative abundance of the cultivable fungi among plant tissues, canopy air, and rhizosphere soil. Panels $\mathbf{A}$ (unique) and $\mathbf{E}$ (97\%) represent roots, panels B (unique) and F (97\%) represent stems, panels C (unique) and G $(97 \%)$ represent leaves, and panels D (unique) and $\mathbf{H}(97 \%)$ represent withered leaves. The overlapping parts of solid circles or ellipses with different colors represent the same OTUs, and the percentage is the relative abundance. The different colored parts of the ring diagrams show the abundance of cultivable endophytic fungi, rhizosphere fungi, and canopy air fungi, respectively.

species have been known for their ability to act as biocontrol agents against plant pathogens (Harman, 2006). It also remains to be explored whether the resistance of these Trichoderma to pathogens indirectly improves the competitiveness of A. adenophora.

Methodologically, because inherent biases are unavoidable for both the culture-dependent and culture-independent methods of investigating fungal diversity (Christian et al., 2017), we selected culture methods primarily to be able to use these cultivable fungi to test their ecological functions in A. adenophora invasion in later experiments. Actually, our smallscale investigation of $A$. adenophora fungi not only revealed that the fungal communities were indeed different between the culture-dependent and culture-independent methods but also that there was a significant tissue specificity (Zhou et al., 2019). Therefore, it is still necessary to combine these two methods for deciphering fungal distribution and interaction inside and outside of A. adenophora. In addition, OTU classification has been widely used in fungal community studies based on the ITS sequence similarity at 100 (Geisen et al., 2017), 99 (Sarmiento et al., 2017), and 97\% (Christian et al., 2017), and this usually results in distinct fungal diversity estimates as well as ecological hypotheses that arise from such observations (Gazis et al., 2011). Similarly, in this study, 100\% sequence identity only showed an above- and belowground differentiation in fungal community composition (Figure 3A), while use of the $97 \%$ sequence identity showed the complete differentiation among roots, stems, leaves, and withered leaves (Figure 3C). Although the comparison of the two OTU classification criteria also showed a slight impact for the Shannon diversity index values (Figures 4, 6), the primary conclusions of this study were not affected.

\section{CONCLUSION}

In conclusion, we found that the invasive plant $A$. adenophora enriched the cultivable endophytic fungi, which showed a significant tissue specificity, and demonstrated that the fungi rarely occurred systemic growth. Our study further revealed that the cultivable endophytic fungi of A. adenophora changed across geographic areas but showed a certain degree of variation in different tissues. Relatively, the cultivable fungi in mature and withered leaves showed more fluctuations than those in roots and stems. We also found that some cultivable endophytic fungi of $A$. adenophora might undergo tissue-to-tissue migration, and the stem could be a transport tissue by which airborne fungi infect roots or vice versa. Finally, we found that the composition of the cultivable fungal community was related to the contiguous environment, which reflects a frequent interaction between fungi associated with $A$. adenophora and those in surrounding environments.

\section{DATA AVAILABILITY STATEMENT}

The datasets generated for this study can be found in GenBank, MK303973-MK304430. 


\section{AUTHOR CONTRIBUTIONS}

KF analyzed the data and wrote the manuscript. Y-FM designed the project, analyzed the data and performed the experiments. KF, LC, JZ, Z-PY, and X-FD collected the samples and performed the experiments. $\mathrm{H}-\mathrm{BZ}$ designed the project and wrote the manuscript. All authors have read and approved the submission of this manuscript.

\section{FUNDING}

All the sources of funding received for the research being submitted had been declared. The funder of this work was the National Natural Science of China, Grant Nos. 31770585 and 31360153. The funder covered all costs

\section{REFERENCES}

Arnold, A. E. (2007). Understanding the diversity of foliar endophytic fungi: progress, challenges, and frontiers. Fungal Biol. Rev. 21, 51-66. doi: 10.1016/ j.fbr.2007.05.003

Arnold, A. E., and Lutzoni, F. (2007). Diversity and host range of foliar fungal endophytes: are tropical leaves biodiversity hotspots? Ecology 88, 541-549. doi: 10.1890/05-1459

Aschehoug, E. T., Metlen, K. L., Callaway, R. M., and Newcombe, G. (2012). Fungal endophytes directly increase the competitive effects of an invasive forb. Ecology 93, 3-8. doi: 10.1890/11-1347.1

Busby, P. E., Ridout, M., and Newcombe, G. (2016). Fungal endophytes: modifiers of plant disease. Plant Mol. Biol. 90, 645-655. doi: 10.1007/s11103-0150412-0

Callaway, R. M., Thelen, G. C., Rodriguez, A., and Holben, W. E. (2004). Soil biota and exotic plant invasion. Nature 427, 731-733. doi: 10.1038/nature 02322

Campisano, A., Albanese, D., Yousaf, S., Pancher, M., Donati, C., and Pertot, I. (2017). Temperature drives the assembly of endophytic communities' seasonal succession. Environ. Microbiol. 19, 3353-3364. doi: 10.1111/1462-2920. 13843

Chi, F., Shen, S. H., Cheng, H. P., Jing, Y. X., Yanni, Y. G., and Dazzo, F. B. (2005). Ascending migration of endophytic rhizobia, from roots to leaves, inside rice plants and assessment of benefits to rice growth physiology. Appl. Environ. Microbiol. 71, 7271-7278. doi: 10.1128/AEM.71.11.7271-7278. 2005

Christian, N., Herre, E. A., Mejia, L. C., and Clay, K. (2017). Exposure to the leaf litter microbiome of healthy adults protects seedlings from pathogen damage. Proc. R. Soc. B 284:20170641. doi: 10.1098/rspb.2017.0641

Crocker, E. V., Karp, M. A., and Nelson, E. B. (2015). Virulence of oomycete pathogens from Phragmites australis-invaded and noninvaded soils to seedlings of wetland plant species. Ecol. Evol. 5, 2127-2139. doi: 10.1002/ece3. 1468

Emi, M., and Kenji, F. (2013). A comparison of fungal endophytic community diversity in tree leaves of rural and urban temperate forests of Kanto district, eastern Japan. Fungal Biol. 117, 191-201. doi: 10.1016/j.funbio.2013. 01.007

Eppinga, M. B., Rietkerk, M., Dekker, S. C., and Ruiter, P. C. D. (2006). Accumulation of local pathogens: a new hypothesis to explain exotic plant invasions. Oikos 114, 168-176. doi: 10.1111/j.2006.0030-1299. 14625.x

Fischer, M. S., and Rodriguez, R. J. (2013). Fungal endophytes of invasive Phagramites australis populations vary in species composition and fungicide susceptibility. Symbiosis 61, 55-62. doi: 10.1007/s13199-013-0261-z

Flory, S. L., Clay, K., and Thrall, P. (2013). Pathogen accumulation and long-term dynamics of plant invasions. J. Ecol. 101, 607-613. doi: 10.1111/1365-2745. 12078 involving into this article, as well as for open access publication fees.

\section{ACKNOWLEDGMENTS}

The authors thank Yi-Shan Chen, Huan Yang, Shou-Neng Baozhu, Tian Zeng, and Wen-Ti Zheng at the Yunnan University for help with partial sampling in the wild.

\section{SUPPLEMENTARY MATERIAL}

The Supplementary Material for this article can be found online at: https://www.frontiersin.org/articles/10.3389/fmicb. 2019.02919/full\#supplementary-material

Gazis, R., Rehner, S., and Chaverri, P. (2011). Species delimitation in fungal endophyte diversity studies and its implications in ecological and biogeographic inferences. Mol. Ecol. 20, 3001-3013. doi: 10.1111/j.1365-294X.2011. 05110.x

Geisen, S., Kostenko, O., Cnossen, M. C., Ten Hooven, F. C., Vres, B., and van der Putten, W. H. (2017). Seed and root endophytic fungi in a range expanding and a related plant species. Front. Microbiol. 8:1645. doi: 10.3389/fmicb.2017. 01645

Glynou, K., Ali, T., Buch, A. K., Haghi Kia, S., Ploch, S., Xia, X., et al. (2016). The local environment determines the assembly of root endophytic fungi at a continental scale. Environ. Microbiol. 18, 2418-2434. doi: 10.1111/1462-2920. 13112

Grayston, S. J., Wang, S., Campbell, C. D., and Edwards, A. C. (1998). Selective influence of plant species on microbial diversity in the rhizosphere. Soil Biol. Biochem. 30, 369-378. doi: 10.1016/s0038-0717(97)00124-7

Harman, G. E. (2006). Overview of mechanisms and uses of Trichoderma spp. Phytopathology 96, 190-194. doi: 10.1094/PHYTO-96-0190

Hodgson, S., de Cates, C., Hodgson, J., Morley, N. J., Sutton, B. C., and Gange, A. C. (2014). Vertical transmission of fungal endophytes is widespread in forbs. Ecol. Evol. 4, 1199-1208. doi: 10.1002/ece3.953

Inderjit, S., Evans, H., Crocoll, C., Bajpai, D., Kaur, R., Feng, Y. L., et al. (2011). Volatile chemicals from leaf litter are associated with invasiveness of a Neotropical weed in Asia. Ecology 92, 316-324. doi: 10.1890/100400.1

Jaber, L. R., and Vidal, S. (2010). Fungal endophyte negative effects on herbivory are enhanced on intact plants and maintained in a subsequent generation. Ecol. Entomol. 35, 25-36. doi: 10.1111/j.1365-2311.2009.01152.x

Kazenel, M. R., Kivlin, S. N., Taylor, D. L., Lynn, J. S., and Rudgers, J. A. (2019). Altitudinal gradients fail to predict fungal symbiont responses to warming. Ecology 100:e02740. doi: 10.1002/ecy.2740

Keane, R. M., and Crawley, M. J. (2002). Exotic plant invasions and the enemy release hypothesis. Trends Ecol. Evol. 17, 164-170. doi: 10.1016/s0169-5347(02) 02499-0

Kogel, K. H., Franken, P., and Huckelhoven, R. (2006). Endophyte or parasite - what decides? Curr. Opin. Plant Biol. 9, 358-363. doi: 10.1016/j.pbi.2006. 05.001

Li, Y. P., Feng, Y. L., Kang, Z. L., Zheng, Y. L., Zhang, J. L., Chen, Y. J., et al. (2017). Changes in soil microbial communities due to biological invasions can reduce allelopathic effects. J. Appl. Ecol. 54, 1281-1290. doi: 10.1111/1365-2664. 12878

Lodge, D. J., Fisher, P. J., and Sutton, B. C. (1996). Endophytic fungi of Manilkara bidentata leaves in Puerto Rico. Mycologia 88, 733-738. doi: 10.2307/376 0967

Lymperopoulou, D. S., Adams, R. I., Lindow, S. E., and Löffler, F. E. (2016). Contribution of vegetation to the microbial composition of nearby outdoor air. Appl. Environ. Microbiol. 82, 3822-3833. doi: 10.1128/aem.0 0610-6 
Malinich, E., Lynn-Bell, N., and Kourtev, P. S. (2017). The effect of the invasive Elaeagnus umbellata on soil microbial communities depends on proximity of soils to plants. Ecosphere 8:e01827. doi: 10.1002/ecs2.1827

Martí, R. E., Cubero, J., Daza, A., Piquer, J., Salcedo, C. I, Morente, C., et al. (1999). Evidence of migration and endophytic presence of Agrobacterium tumefaciens in rose plants. Eur. J. Plant pathol. 105, 39-50.

Martiny, J. B., Bohannan, B. J., Brown, J. H., Colwell, R. K., Fuhrman, J. A., Green, J. L., et al. (2006). Microbial biogeography: putting microorganisms on the map. Nat. Rev. Microbiol. 4, 102-112. doi: 10.1038/nrmicro1341

Mei, L., Zhu, M., Zhang, D. Z., Wang, Y. Z., Guo, J., and Zhang, H. B. (2014). Geographical and temporal changes of foliar fungal endophytes associated with the invasive plant Ageratina adenophora. Microb. Ecol. 67, 402-409. doi: 10. 1007/s00248-013-0319-8

Mitchell, C. E., Blumenthal, D., Jarosik, V., Puckett, E. E., and Pysek, P. (2010). Controls on pathogen species richness in plants' introduced and native ranges: roles of residence time, range size and host traits. Ecol. Lett. 13, 1525-1535. doi: 10.1111/j.1461-0248.2010.01543.x

Mitchell, C. E., and Power, A. G. (2003). Release of invasive plants from fungal and viral pathogens. Nature 421, 625-627. doi: 10.1038/nature01317

Mucciarelli, M., Scannerini, S., Bertea, C., and Maffei, M. (2003). In vitro and in vivo peppermint (Mentha piperita) growth promotion by nonmycorrhizal fungal colonization. New Phytol. 158, 579-591. doi: 10.1046/j.1469-8137.2003. 00762.x

Müller, C., and Krauss, J. (2005). Symbiosis between grasses and asexual endophytes. Curr. Opin. Plant Biol. 8, 450-456. doi: 10.1016/j.pbi.2005.05.007

Newcombe, G., Shipunov, A., Eigenbrode, S., Raghavendra, A., Ding, H., Anderson, C., et al. (2009). Endophytes influence protection and growth of an invasive plant. Commun. Integr. Biol. 2, 29-31. doi: 10.4161/cib.2.1.7393

Newsham, K. K. (2011). A meta-analysis of plant responses to dark septate root endophytes. New Phytol. 190, 783-793. doi: 10.1111/j.1469-8137.2010.03611.x

O'Connell, R. J., Thon, M. R., Hacquard, S., Amyotte, S. G., Kleemann, J., Torres, M. F., et al. (2012). Lifestyle transitions in plant pathogenic Colletotrichum fungi deciphered by genome and transcriptome analyses. Nat. Genet. 44, 1060-1065. doi: 10.1038/ng.2372

Photita, W., Lumyong, S., Lumyong, P., McKenzie, E. H. C., and Hyde, K. D. (2004). Are some endophytes of Musa acuminata latent pathogens? Fungal Divers. 16, 131-140.

Ritpitakphong, U., Falquet, L., Vimoltust, A., Berger, A., Metraux, J. P., and L'Haridon, F. (2016). The microbiome of the leaf surface of Arabidopsis protects against a fungal pathogen. New Phytol. 210, 1033-1043. doi: 10.1111/nph.13808

Rodriguez, R. J., Henson, J., Van Volkenburgh, E., Hoy, M., Wright, L., Beckwith, F., et al. (2008). Stress tolerance in plants via habitat-adapted symbiosis. ISME J. 2, 404-416. doi: 10.1038/ismej.2007.106

Rodriguez, R. J., White, J. F. Jr., Arnold, A. E., and Redman, R. S. (2009). Fungal endophytes: diversity and functional roles. New Phytol. 182, 314-330. doi: 10. 1111/j.1469-8137.2009.02773.x

Romero, A., Carrion, G., and Rico-Gray, V. (2001). Fungal latent pathogens and endophytes from leaves of Parthenium hysterophorus (Asteraceae). Fungal Divers. 7, 81-87.

Rudgers, J. A., Mattingly, W. B., and Koslow, J. M. (2005). Mutualistic fungus promotes plant invasion into diverse communities. Oecologia 144, 463-671. doi: 10.1007/s00442-005-0039-y

Ryberg, M. (2015). Molecular operational taxonomic units as approximations of species in the light of evolutionary models and empirical data from Fungi. Mol. Ecol. 24, 5770-5777. doi: 10.1111/mec.13444

Saleem, M., Meckes, N., Pervaiz, Z. H., and Traw, M. B. (2017). Microbial interactions in the phyllosphere increase plant performance under herbivore biotic stress. Front. Microbiol. 8:41. doi: 10.3389/fmicb.2017.00041

Sarmiento, C., Zalamea, P. C., Dalling, J. W., Davis, A. S., Stump, S. M., U’Ren, J. M., et al. (2017). Soilborne fungi have host affinity and host-specific effects on seed germination and survival in a lowland tropical forest. Proc. Natl. Acad. Sci. U.S.A. 114, 11458-11463. doi: 10.1073/pnas.1706324114

Schloss, P. D., Westcott, S. L., Ryabin, T., Hall, J. R., Hartmann, M., Hollister, E. B., et al. (2009). Introducing mothur: open-source, platform-independent, community-supported software for describing and comparing microbial communities. Appl. Environ. Microbiol. 75, 7537-7541. doi: 10.1128/aem. 01541-9
Shi, Y., Li, C., Yang, H., Zhang, T., Gao, Y., Zeng, J., et al. (2016). Endophytic fungal diversity and space-time dynamics in sugar beet. Eur. J. Soil Biol. 77, 77-85. doi: 10.1016/j.ejsobi.2016.09.005

Shipunov, A., Newcombe, G., Raghavendra, A. K., and Anderson, C. L. (2008). Hidden diversity of endophytic fungi in an invasive plant. Am. J. Bot. 95, 1096-1108. doi: 10.3732/ajb.0800024

Stewart, C. N. Jr., and Via, L. E. (1993). A rapid CTAB DNA isolation technique useful for RAPD fingerprinting and other PCR applications. Biotechniques 14, $748-750$.

Stricker, K. B., Harmon, P. F., Goss, E. M., Clay, K., and Luke Flory, S. (2016). Emergence and accumulation of novel pathogens suppress an invasive species. Ecol. Lett. 19, 469-477. doi: 10.1111/ele.12583

Ter Braak, C. J. F., and Šmilauer, P. (2012). Canoco Reference Manual and User's Guide: Software for Ordination (version 5.0). Wageningen: Microcomputer power.

Tharek, M., Dzulaikha, K., Salwani, S., Amir, H. G., and Najimudin, N. (2011). Ascending endophytic migration of locally isolated diazotroph, Enterobacter $\mathrm{sp}$. strain USML2 in rice. Biotechnology 10, 521-527. doi: 10.3923/biotech.2011. 521.527

Thompson, J. D., Gibson, T. J., Plewniak, F., Jeanmougin, F., and Higgins, D. G. (1997). The CLUSTAL_X windows interface: flexible strategies for multiple sequence alignment aided by quality analysis tools. Nucleic Acids Res. 25, 4876-4882. doi: 10.1093/nar/25.24.4876

Torres-Cortes, G., Bonneau, S., Bouchez, O., Genthon, C., Briand, M., Jacques, M. A., et al. (2018). Functional microbial features driving community assembly during seed germination and emergence. Front. Plant Sci. 9:902. doi: 10.3389/ fpls.2018.00902

van der Heijden, M. G., Bardgett, R. D., and van Straalen, N. M. (2008). The unseen majority: soil microbes as drivers of plant diversity and productivity in terrestrial ecosystems. Ecol. Lett. 11, 296-310. doi: 10.1111/j.1461-0248.2007. 01139.x

van der Putten, W. H., Bardgett, R. D., Bever, J. D., Bezemer, T. M., Casper, B. B., Fukami, T., et al. (2013). Plant-soil feedbacks: the past, the present and future challenges. J. Ecol. 101, 265-276. doi: 10.1111/1365-2745.12054

van der Putten, W. H., Klironomos, J. N., and Wardle, D. A. (2007). Microbial ecology of biological invasions. ISME J. 1, 28-37. doi: 10.1038/ismej.2007.9

Vilà, M., Basnou, C., Pyšek, P., Josefsson, M., Genovesi, P., Gollasch, S., et al. (2010). How well do we understand the impacts of alien species on ecosystem services? A pan-European, cross-taxa assessment. Front. Ecol. Environ. 8:135-144. doi: $10.1890 / 080083$

Wang, R., and Wang, Y.-Z. (2006). Invasion dynamics and potential spread of the invasive alien plant species Ageratina adenophora (Asteraceae) in China. Divers. Distrib. 12, 397-408. doi: 10.1111/j.1366-9516.2006.00250.x

Wang, W. B., Wang, R. F., Lei, Y. B., Liu, C., Han, L. H., Shi, X. D., et al. (2013). High resource capture and use efficiency and prolonged growth season contribute to invasiveness of Eupatorium adenophorum. Plant Ecol. 214, 857868. doi: 10.1007/s11258-013-0214-x

Wearn, J. A., Sutton, B. C., Morley, N. J., and Gange, A. C. (2012). Species and organ specificity of fungal endophytes in herbaceous grassland plants. J. Ecol. 100, 1085-1092. doi: 10.1111/j.1365-2745.2012.01997.x

Whitaker, B. K., Bauer, J. T., Bever, J. D., and Clay, K. (2017). Negative plantphyllosphere feedbacks in native Asteraceae hosts - a novel extension of the plant-soil feedback framework. Ecol. Lett. 20, 1064-1073. doi: 10.1111/ele. 12805

Xu, C. W., Yang, M. Z., Chen, Y. J., Chen, L. M., Zhang, D. Z., Mei, L., et al. (2012). Changes in non-symbiotic nitrogen-fixing bacteria inhabiting rhizosphere soils of an invasive plant Ageratina adenophora. Appl. Soil Ecol. 54, 32-38. doi: 10.1016/j.apsoil.2011.10.021

Yahdjian, L., Gherardi, L., and Sala, O. E. (2011). Nitrogen limitation in aridsubhumid ecosystems: a meta-analysis of fertilization studies. J. Arid Environ. 75, 675-680. doi: 10.1016/j.jaridenv.2011.03.003

Yamamoto, N., and Bibby, K. (2014). Clustering of fungal community internal transcribed spacer (ITS) sequence data obscures taxonomic diversity. Environ. Microb. 16, 2491-2500. doi: 10.1111/1462-2920.12390

Yan, J. F., Broughton, S. J., Yang, S. L., and Gange, A. C. (2015). Do endophytic fungi grow through their hosts systemically? Fungal Ecol. 13, 53-59. doi: 10. 1016/j.funeco.2014.07.005 
Yokoya, K., Postel, S., Fang, R., and Sarasan, V. (2017). Endophytic fungal diversity of Fragaria vesca, a crop wild relative of strawberry, along environmental gradients within a small geographical area. PeerJ 5:e2860. doi: 10.7717/peerj. 2860

Zhou, J., Miao, Y. F., Fang, K., Chen, L., Yang, Z. P., Dong, X. F., et al. (2019). Diversity of the endophytic and rhizosphere soil fungi of Ageratina adenophora. Ecol. Sci. 38, 1-7. doi: 10.14108/j.cnki.1008-8873.2019.05.001

Zhu, X. Z., Li, Y. P., Feng, Y. L., and Ma, K. P. (2017). Response of soil bacterial communities to secondary compounds released from Eupatorium adenophorum. Biol. Invasions 19, 1471-1481. doi: 10.1007/s10530-017$1371-\mathrm{y}$
Conflict of Interest: The authors declare that the research was conducted in the absence of any commercial or financial relationships that could be construed as a potential conflict of interest.

Copyright (c) 2019 Fang, Miao, Chen, Zhou, Yang, Dong and Zhang. This is an open-access article distributed under the terms of the Creative Commons Attribution License (CC BY). The use, distribution or reproduction in other forums is permitted, provided the original author(s) and the copyright owner(s) are credited and that the original publication in this journal is cited, in accordance with accepted academic practice. No use, distribution or reproduction is permitted which does not comply with these terms. 